\title{
AVANÇOS RECENTES EM BIOSSÍNTESE COMBINATÓRIA DE POLICETÍDEOS: PERSPECTIVAS E DESAFIOS
}

\author{
Bruno S. Paulo ${ }^{a}$, Renata Sigrist ${ }^{\mathrm{a}}$ e Luciana G. de Oliveira*a. \\ a'Departamento de Química Orgânica, Instituto de Química, Universidade Estadual de Campinas, 13083-970 Campinas - SP, Brasil
}

Recebido em 01/08/2018; aceito em 23/10/2018; publicado na web em 07/11/2018

\begin{abstract}
RECENT ADVANCES IN COMBINATORIAL BIOSYNTHESIS OF POLYKETIDES: PERSPECTIVES AND CHALLENGES. Natural products continue to inspire scientists on the search for biological active structures. Recent advances in synthetic biology allow modifying genes to extend structural diversity present on natural products by changing important functional groups guided through genetic information. In this context, polyketides synthases (PKS) represent a class of enzymes from where the first applications and well succeed modifications were achieved. During the last two decades PKSs have been extensively studied, sequenced and deposited in data banks available to scientific community around the world. This newly wide information associated to different methodologies accessible to modify the PKSs genetic circuits including genetic insertion, gene deletion and gene replacement leads to discovery of new natural products. In this review, the recent advances in combinatorial biosynthesis, as well as modern techniques in synthetic biology to promote structural diversity on natural products will be discussed.
\end{abstract}

Keywords: polyketides; combinatorial biosynthesis; polyketide synthases; synthetic biology.

\section{INTRODUÇÃO}

Os produtos naturais realizam papel fundamental na descoberta de fármacos e na compreensão dos principais mecanismos de ação de uma molécula ativa, sendo o principal interesse nessas estruturas relacionado à ampla participação clínica que apresentam.${ }^{1,2}$ No último levantamento realizado por Newmann \& Cragg, ${ }^{3}$ entre os anos de 1981 e 2014, foi observado que entre as 1211 micromoléculas aprovadas como fármacos pelo FDA (Food and Drug Administration), cerca de $65 \%$ possuem uma profunda correlação com as estruturas encontradas nos produtos naturais ou são derivados diretos de alguma fonte biológica.

Nesse sentido, a habilidade de estender a química da natureza possibilita a alteração de grupos funcionais, a estereoquímica e os esqueletos naturais por aproximações sintéticas e também pela manipulação genética de enzimas participantes da biossíntese, oferecendo múltiplas oportunidades para obtenção de análogos estruturais ${ }^{4} \mathrm{e}$, com isso, aprimorar a efetividade de um fármaco.

Entre os metabólitos com maior taxa de efetividade, aqueles oriundos das sintases de policetídeos (PKS) destacam-se por possuírem diversas aplicações, atuando como redutores dos níveis de colesterol (lovastatina 1), ${ }^{5}$ antibióticos (eritromicina 2), ${ }^{6}$ antifúngicos (anfotericina 3), ${ }^{7}$ anti-tuberculose (avermectina 4), ${ }^{8}$ antineoplásicos (doxorubicina 5, salinomicina 6 $)^{9,10}-$ (Figura 1). Uma característica interessante desse grupo heterogêneo de estruturas, que compreende poliéteres, polienos, polifénois, macrolídeos e enediinos, é que todos são derivados de um dos blocos mais simples da natureza, o acetato.

Apesar do continuo esforço para a prospecção de novos policetídeos, o re-isolamento de substâncias já conhecidas associado à baixa produção desses alvos e o alto custo envolvido na triagem metabólica representaram fatores desestimulantes para a indústria farmacêutica. ${ }^{11}$ Com o advento das técnicas de biologia molecular e da rapidez e barateamento do sequenciamento de genomas completos, a engenharia genética, aliada à biotecnologia e à síntese química, inspirou-se nas grandes bibliotecas produzidas pela química combinatória para desenvolver um conjunto de técnicas de manipulações do maquinário biossintético de um organismo com o intuito de promover

*e-mail: luciana@iqm.unicamp.br alterações estruturais nos compostos biossintetizados naturalmente. Nesse sentido, o termo "biossíntese combinatória" remete ao potencial de rearranjar e modificar genes para a produção de bibliotecas de produtos naturais, fundamentais para traçar o limiar entre estrutura e atividade biológica existente na concepção de um fármaco.

Os pioneiros nessa área foram Hopwood e colaboradores ${ }^{12}$ que em 1985, produziram modificações na via de biossíntese da actinohordina (7) através da inserção do correspondente agrupamento (cluster) biossintético em diversas espécies de Streptomyces. As alterações resultaram na biossíntese dos análogos granaticina $(\mathbf{8})$ e medermicina (9). Modificações na linhagem nativa, através da inserção de genes, permitiram a caracterização da mederhordina A (10), di-hidrogranaticina (11) e di-hidrogranatirhodina (12), evidenciando a possibilidade de realizar modificações na natureza química dos metabólitos através da manipulação de vias análogas (Figura 2).

A partir desse trabalho pioneiro, novas explorações a respeito da natureza genética dos produtos naturais foram revisadas, impulsionando a biossíntese combinatória de policetídeos como uma área de pesquisa especialmente interessada em metodologias de recombinação homóloga para promover diversidade enzimática (e consequentemente diversidade estrutural) fazendo uso de organismos heterólogos mais sofisticados para ampliar o conhecimento sobre as PKSs. Adicionalmente, o desenvolvimento das plataformas de armazenamento, disponibilização e elucidação funcional das sequências de genes dos clusters biossintéticos contribuiu para a evolução dessa área. Portanto, compreender a química envolvida nas vias de biossíntese e a biologia dos organismos produtores é de crucial importância para a obtenção de modificações estruturais a partir da informação genética.

\section{BIOSSÍNTESE DE POLICETÍDEOS}

Os policetídeos são uma classe de produtos naturais biossintetizados por grandes blocos enzimáticos multimodulares, denominados sintases de policetídeos (PKS). Essas megassintases ( 900 kDa) apresentam muitas características em comum com a biossíntese de ácidos graxos, ${ }^{13}$ não somente no que diz respeito aos mecanismos envolvidos na condensação dos substratos, mas também em relação aos precursores empregados para construção das cadeias, usualmente 
<smiles>CCC(C)C(=O)O[C@H]1C[C@H](C)C=C2C=C[C@H](C)[C@H](CCC3C[C@H](O)CC(=O)O3)[C@H]21</smiles>

Lovastatina (1)

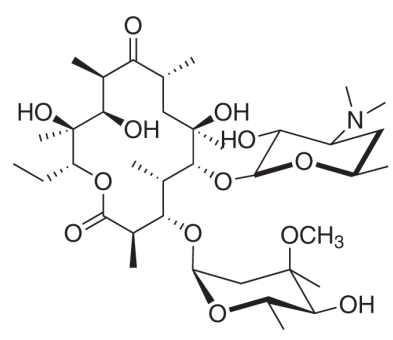

Eritromicina (2)

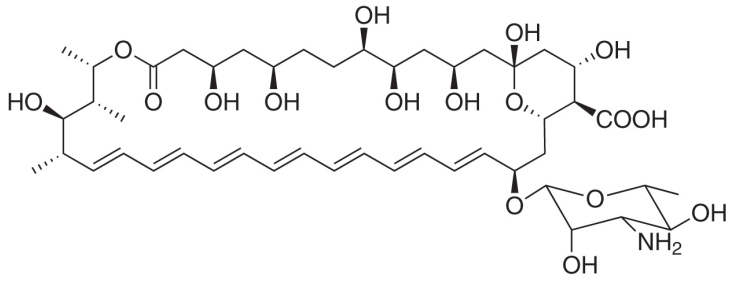

Anfotericina (3)

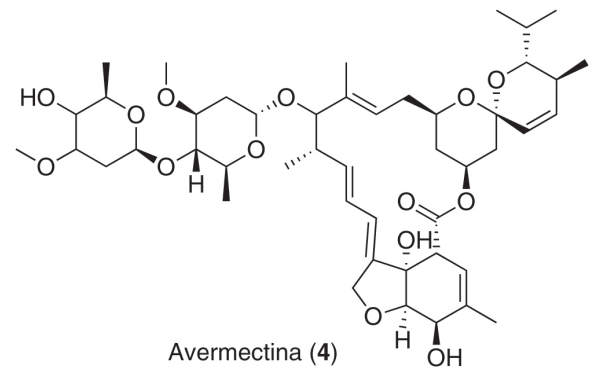<smiles>COc1cccc2c1C(=O)c1c(O)c3c(c(O)c1C2=O)C[C@@H](OC1C[C@H](N)[C@H](O)[C@H](C)O1)C[C@H]3C(=O)CO</smiles>

Doxorubicina (5)

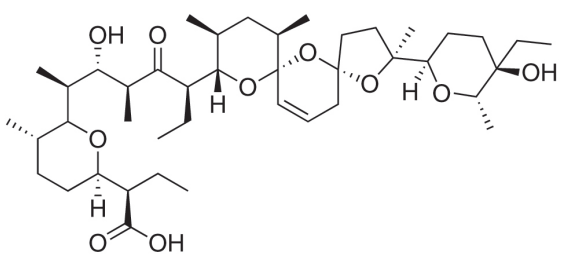

Salinomicina (6)

Figura 1. Estruturas representativas de policetídeos com atividade biológica<smiles></smiles>

Actinohordina (7)

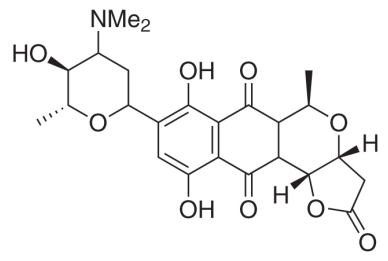

Mederhordina A (10)

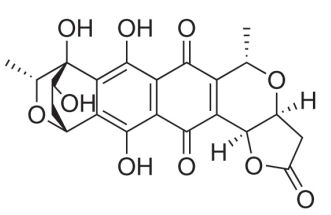

Granaticina (8)

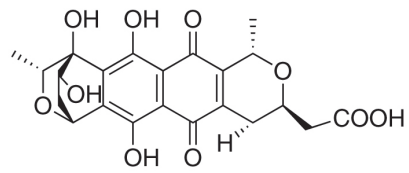

Dihidrogranaticina (11)<smiles>CC1O[C@H]2CC(=O)O[C@H]2[C@@H]2C(=O)c3ccc([C@@H]4CC(N(C)C)[C@H](O)[C@H](C)O4)c(O)c3C(=O)C12</smiles>

Medermicina (9)

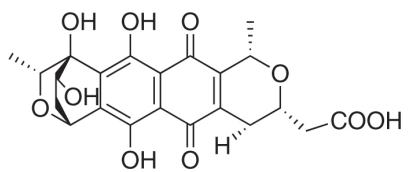

Dihidrogranatirhordina (12)

Figura 2. Estruturas química dos antibióticos isocromaquinolínicos

são utilizados unidades de metilmalonil-CoA, propanoil-CoA e acetil-CoA. A principal diferença, no entanto, é que normalmente a biossíntese de ácidos graxos resulta no produto completamente reduzido a cada ciclo de extensão, já durante a biossíntese dos policetídeos, a redução é variável. ${ }^{14}$

As PKSs estão presentes em bactérias, fungos e plantas ${ }^{15} \mathrm{e}$ divididas em três tipos, classificadas de acordo com sua estrutura e funcionalidade. PKSs do tipo I, normalmente encontradas em bactérias e fungos, são amplamente estudadas e apresentam o maquinário biossintético dividido em módulos, os quais se subdividem em vários domínios. Podem atuar de modo iterativo (domínios se repetem durante a biossíntese) ou não iterativo (canônico), onde cada ciclo de extensão da cadeia policetídica é realizado por um módulo específico e os domínios não se repetem (Figura 3). As PKSs do tipo II, se apresentam como um complexo de proteínas dissociável e possuem um único conjunto de domínios com atividade iterativa, sendo essas muito comuns para a formação de compostos aromáticos em bactérias, como a doxorubicina (5). Por último, as PKSs do tipo III possuem estrutura homodimérica, ação interativa e não são dependentes de ACP para carregar a cadeia extensora. Estão presentes principalmente em plantas, atuando na biossíntese de flavonoides e chalconas, como a narigenina (7). Algumas bactérias e fungos também possuem essas organizações do tipo III atuando na produção de policetídeos como a flaviolina ${ }^{16,17}$ (Figura 3).

Um módulo usual de PKS do tipo I deve conter no mínimo 3 domínios essenciais: domínio de cetoacila sintase (KS), responsável por catalisar a formação de uma ligação C-C através de uma condensação descarboxilativa, um domínio de acetiltranferase (AT), responsável por recrutar uma unidade extensora e uma proteína carreadora de acila (ACP), que participa como um carregador da cadeia policetídica em formação. Essa classe possui também variações nos domínios AT sendo trans-AT ${ }^{18}$ quando não estão posicionados subsequente (alinhados) aos demais domínios ou cis-AT, quando alinhados. Ao final de todos os módulos, o domínio de tioesterase (TE) é responsável pela transesterificação do policetídeo retirando-o do complexo enzimático. Essa clivagem pode ser intramolecular, levando a formação de macrolactonas, ou por hidrólise, levando a formação de um grupo ácido carboxílico. 


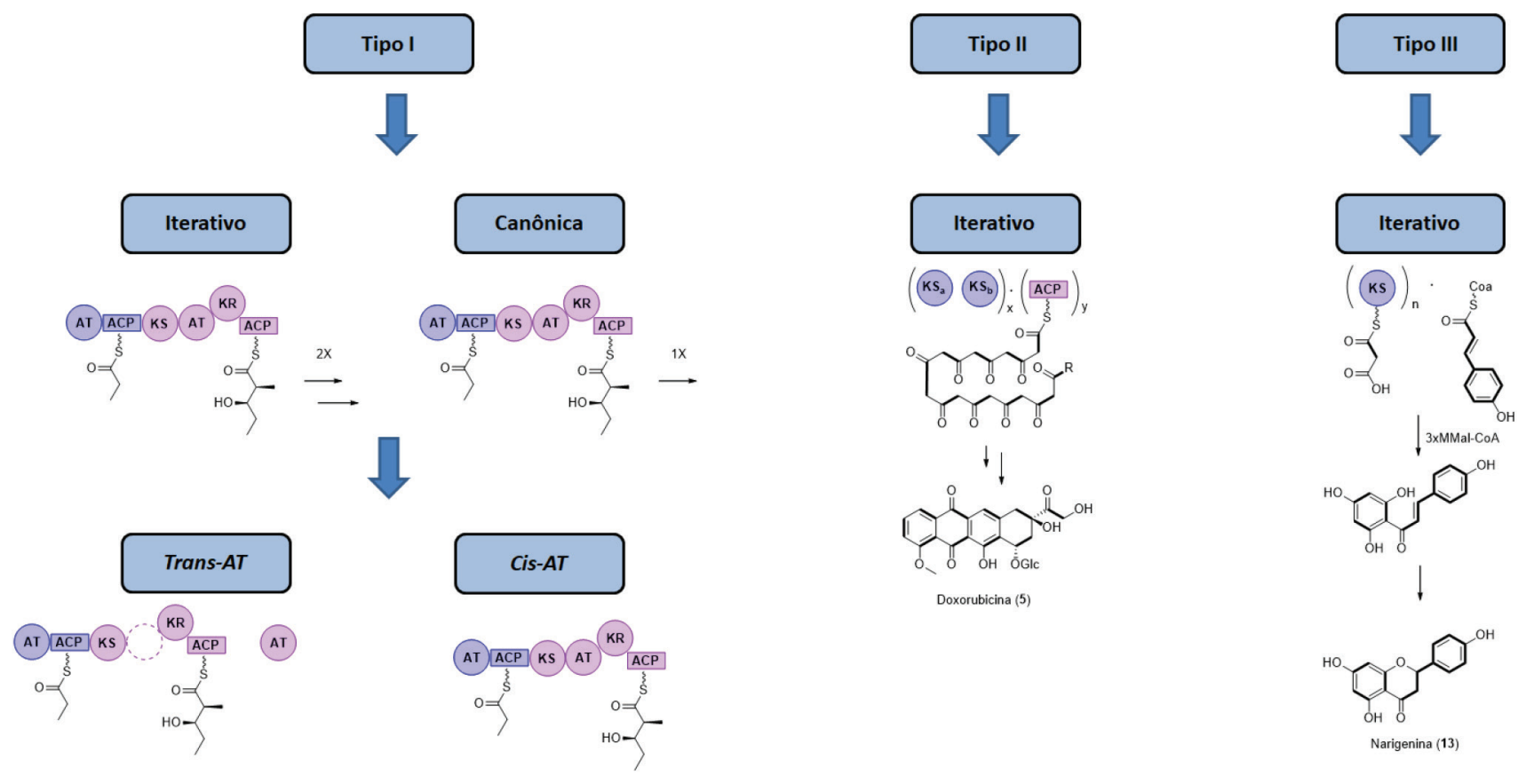

Figura 3. Classificação das sintases de policetídeos com relação a sua estrutura (tipo I, tipo II e tipo III), do modo de condensação dos substratos (iterativo ou canônico) e com relação a colinearidade dos domínios AT (trans-AT ou cis-AT)

Outros domínios modificadores são facultativos, tais como a cetorredutase (KR), responsável pela redução da carbonila ao álcool, a desidratase (DH), que elimina água levando a formação da olefina e a enoila redutase (ER), que converte a olefina na cadeia saturada. ${ }^{15}$ A via biossintética da eritromicina em Saccharopolyspora erythraea, completamente elucidada pelos grupos dos professores Leadlay ${ }^{19} \mathrm{e}$ $K t^{20}$ na década de 90 , compreende um dos exemplos mais didáticos para o estudo dos mecanismos das PKSs do tipo I (Figura 4).

Inicialmente, devemos notar que apenas 3 genes completos são responsáveis pela formação do núcleo aglicona (6-deoxieritronolídeo B), esses genes foram intitulados eryA-I, eryA-II e eryA-III e codificam as proteínas (DEBSI, DEBSII e DEBSIII) que atuam de forma linear na biossíntese da eritromicina. A primeira unidade inserida no módulo iniciador é o propanoil-CoA e cada unidade AT subsequente é responsável pela incorporação de um substrato, que nesse caso em específico é uma unidade de metilmalonil-CoA. Os modificadores mais comuns encontrados são as cetorredutases (KR), que promovem de forma estereosseletiva a redução do grupo carbonila ao álcool correspondente e o módulo 4 apresenta o maior número de domínios modificadores, levando a redução completa do grupo carbonílico. No último módulo, o domínio TE é responsável pela transesterificação intramolecular e formação do núcleo macrolactônico.

\section{Primeiras experiências utilizando a biossíntese combinatória em policetídeos}

Inicialmente, a biossíntese combinatória foi realizada em policetídeos microbianos visando estudar principalmente PKSs bem estabelecidas e que se utilizavam de substratos simples da via metabólica do acetato, como malonatos, propanoatos e derivados. O que realmente incitou os pesquisadores foi a linearidade (módulos e domínios) presente na "montagem" das PKSs do tipo I. Essa característica modular propiciou uma série de pesquisas envolvendo a manipulação genética desses módulos na tentativa de promover alterações estruturais nos esqueletos dos policetídeos.

A primeira demonstração da viabilidade de engenharia genética para a produção de macrolídeos estruturalmente modificados foi apresentada pelo grupo do Katz, ${ }^{20}$ que inibiu o domínio de KR, presente no módulo 5, por alteração da sequência primária, levando ao produto 5-ceto (14) em vez do original 5-hidróxi. Esse novo produto não apresentou atividade antibiótica, mas experimentalmente forneceu a primeira evidência de que novos produtos naturais policetídicos poderiam ser produzidos por engenharia genética (Figura 5A).

O próximo desafio, a partir de então, surgiu da motivação de provar que seria possível reposicionar domínios TE para a produção de policetídeos de cadeias menores. ${ }^{21,22}$ Isso envolveu a adição de uma cópia do domínio TE (DEBSIII) ao final da sequência de DEBSI. O mutante resultante (DEBSI-TE) foi capaz de produzir uma lactona tricetídica (15) em vez do macrolídeo original de 14-membros (Figura 5B).

Outras estratégias para modificar os domínios funcionais das PKSs foram propostas na tentativa de alterar os substratos inseridos no esqueleto principal dos policetídeos, a partir da transferência de um domínio AT de outra PKS para formar uma sintase quimérica. O encorajamento surgiu do fato que as PKSs do tipo I possuem estruturas próximas umas das outras e seguem os mesmos princípios de operação. O primeiro exemplo de produção de uma PKS quimérica envolveu a substituição de um domínio de AT (específico para malonato) oriundo da PKS responsável pela biossíntese de rapamicina na DEBSI-TE. ${ }^{23} \mathrm{O}$ mutante resultante foi capaz de produzir a lactona tricetídica (16) com um substituinte metila a menos na posição prevista (Figura 5C).

Nesse contexto, centenas de produtos "não-naturais" foram projetados, principalmente àqueles provenientes das PKSs do tipo I. Os trabalhos em biossíntese combinatória apoiaram-se na manipulação do substrato inserido nas "linhas de montagem", utilizando as mais variadas técnicas de biologia molecular, incluindo a fusão de genes, inativação de genes, substituição genética, alteração dos domínios enzimáticos e troca de módulos de forma a produzir diversidade estrutural $^{24}$ e até mesmo demonstrar aspectos evolutivos das PKSs do tipo I. Sugimoto e colaboradores ${ }^{25}$ exploraram a engenharia da biossíntese da luteroreticulina (17). Nesse exemplo, o grupo partiu de uma PKS análoga responsável pela biossíntese da aurethina (18) e por deleções e inserções gênicas nos módulos previstos foi possível 


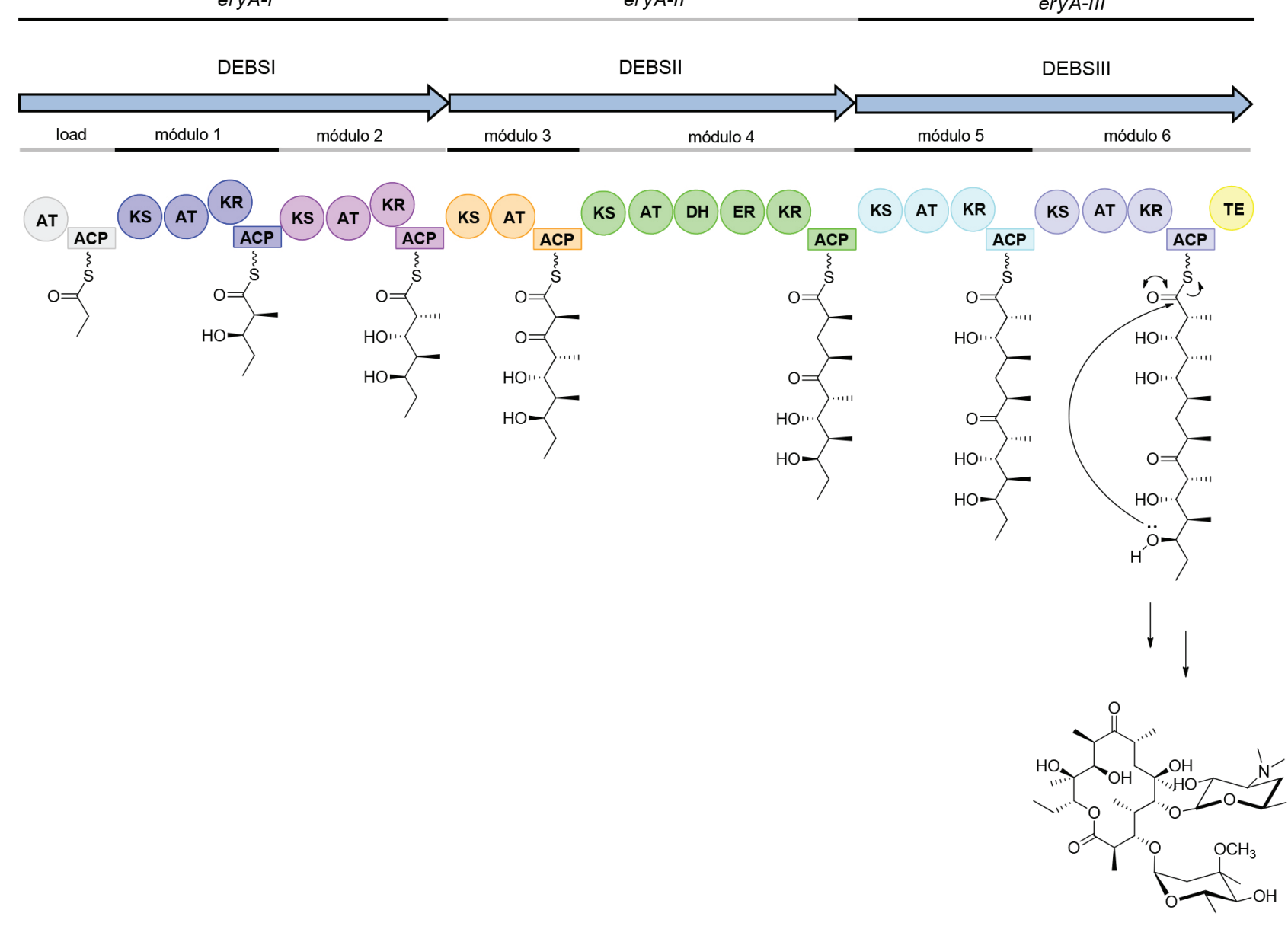

Eritromicina (2)

Figura 4. Modelo de biossintese proposto para a eritromicina em Saccharopolyspora erythraea ${ }^{19,20}$

A

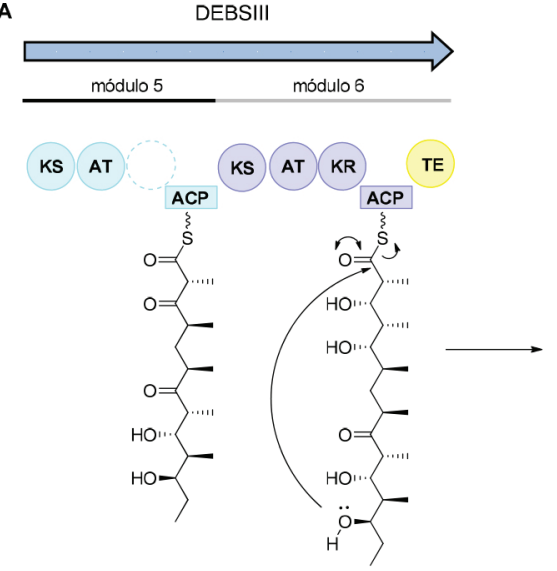

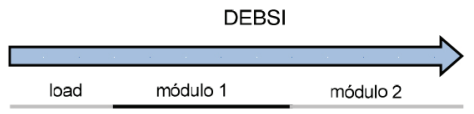

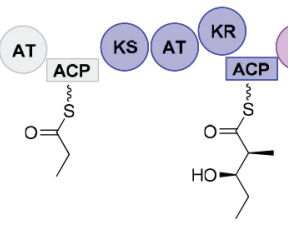

AT $K R$
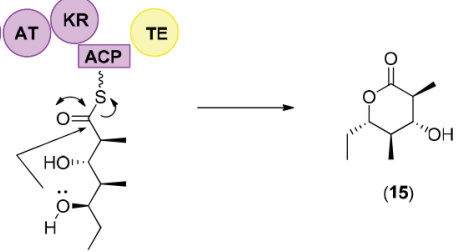

C

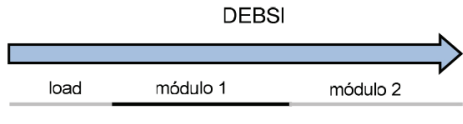

5-ceto macrolídeo (14)
(15)<smiles>CCC1CC(O)C(C)C(=O)O1</smiles>

(16)

Figura 5. Diversidade estrutural obtida por biossíntese combinatória para a produção de análogos da eritromicina: A) Modificação no domínio de cetorredutase do quinto módulo levou a produção do macrolídeo ceto; B) Reposicionamento da TE no final do segundo módulo levou a produção da lactona tricetídica prevista; C) Substituição de um domínio AT específico para malonato oriundo da biossíntese da rapamicina levou a produção de uma lactona tricetídica com uma metila a menos como previsto 
modificar a produção de aurethina para luteoreticulina, além da obtenção de análogos em organismos heterólogos (Figura 6).

\section{Expandindo a diversidade enzimática para a produção de policetídeos}

Até o início dos anos 2000, o maior obstáculo para a área de biossíntese combinatória era a baixa disponibilidade de sequências de DNA, menos de 20 clusters de genes de PKSs haviam sido devidamente sequenciados até a virada do milênio. ${ }^{26}$ Dessa forma, o conhecimento da diversidade biossintética além de caro era muito escasso e dispendioso, levando a evoluções lentas. No entanto, o avanço das técnicas de sequenciamento de DNA permitiu que a área de biossíntese combinatória alcançasse um conhecimento inesperado com relação ao conteúdo biossintético presente nos organismos.

A actinobactéria Streptomyces coelicolor foi a primeira a ser sequenciada, ${ }^{27}$ sendo identificado uma quantidade maior de clusters biossintéticos presentes no genoma desse microrganismo em comparação aos metabólitos que eram observados em condições de cultivo. Até o sequenciamento, apenas quatro metabólitos eram conhecidos, sendo três antibióticos e um pigmento. Porém, a informação codificada no genoma sequenciado apresentou mais de 20 clusters que direcionavam para os mais diversos tipos de entidades relacionadas ao metabolismo secundário. ${ }^{28,29}$ Essa informação apresentada pelo genoma de $S$. coelicolor revelou um potencial para a presença de genes biossintéticos que estavam codificados no genoma, porém não eram completamente acessados sob as condições de cultivo, ou se apresentavam silenciados. ${ }^{29}$

A evolução dos métodos de sequenciamento completo de genomas resultou na descoberta exponencial de clusters de genes crípticos ou órfãos, ou seja, grupos de genes que não possuem entidade identificada ou associada. O número de agrupamentos de genes sequenciados e anotados tem propiciado um crescimento no repertório de módulos e domínios enzimáticos, bem como na descoberta de diferentes arquiteturas de PKSs, como as que apresentam domínios trans-AT. ${ }^{30}$

Com o objetivo de ampliar o conhecimento por rotas biossintéticas responsáveis pela produção de produtos naturais desconhecidos, inúmeras plataformas de depósito e pareamento de genes, ${ }^{31}$ tais como o antiSMASH ${ }^{32}$ (antibiotics \& Secondary Metabolite Analysis Shell (bactérias, fungos e plantas)), SMURF (Secondary Metabolite Unique Regions Finder (fungos)), ${ }^{33} \mathrm{MIBiG}$ (Minimal Information about Biosynthetic Gene Cluster) e PRISM3 (Prediction Informatics for Secondary Metabolomes), ${ }^{34}$ se desenvolveram de maneira a viabilizar ferramentas de retrobiossíntese ${ }^{35}$ (Figura 7A). Nessas plataformas, os dados de um sequenciamento total de genoma são comparados com dados depositados anteriormente e são apresentados hits para os prováveis clusters responsáveis pelo metabolismo secundário. A medida que um cluster é associado a um metabólito, a base de dados renova e armazena essa informação. Dessa maneira, é possível conectar os genes às funções biossintéticas e aos metabólitos codificados, permitindo, por exemplo, estudar a diversidade estrutural entre os organismos nas mais diferentes regiões do globo, além de auxiliar no desenvolvimento da engenharia genética, uma vez que é possível desenhar um circuito de genes in silico com base nas combinações dos módulos, o qual posteriormente é transferido para uma célula viva.

Outros repositórios com funções semelhantes estão surgindo nesse cenário, como é o caso das plataformas voltadas para a desreplicação dos dados de espectrometria de massas. O GNPS (Global Natural Products Social Molecular Networking $)^{36}$ consiste em uma
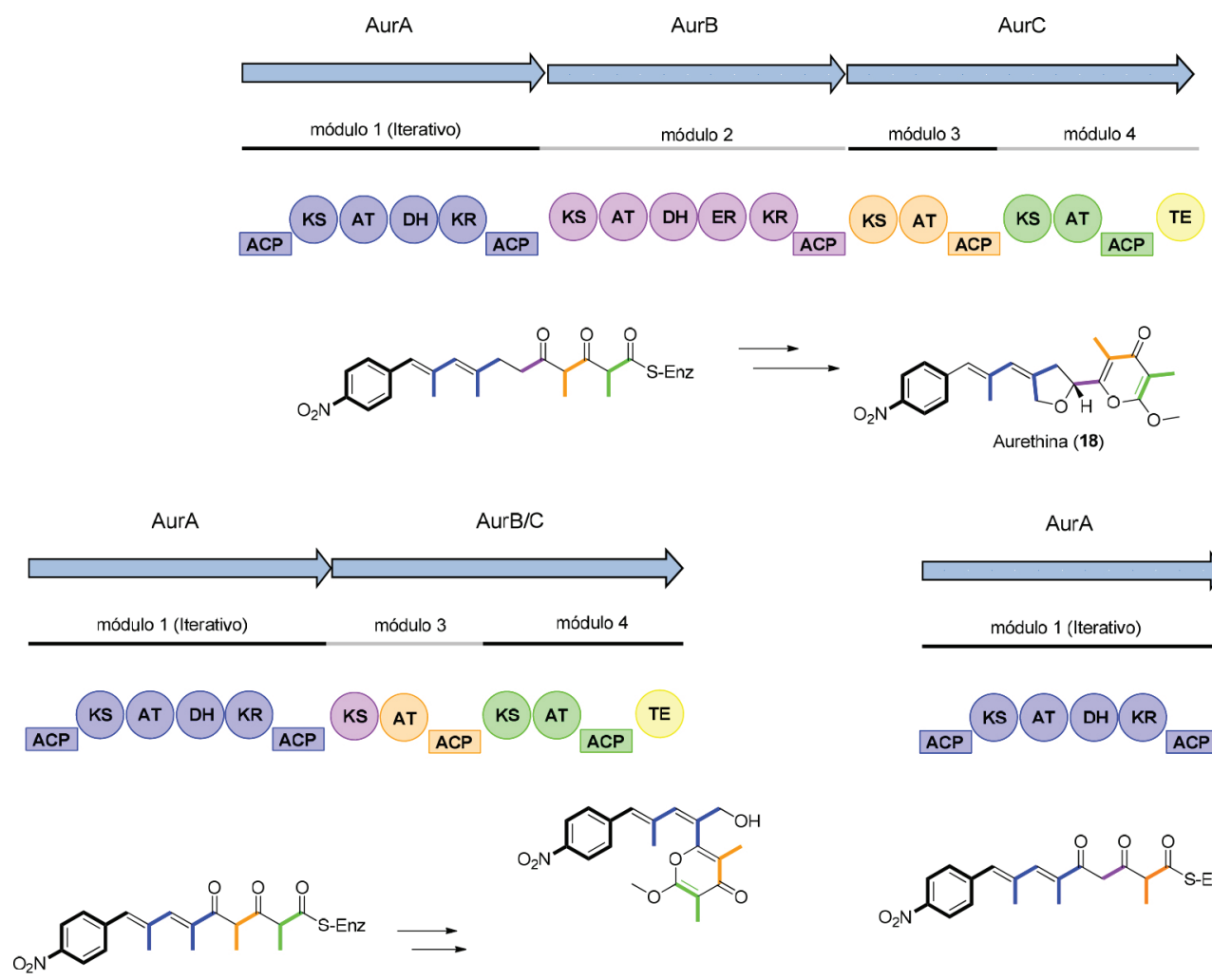

AurB/C
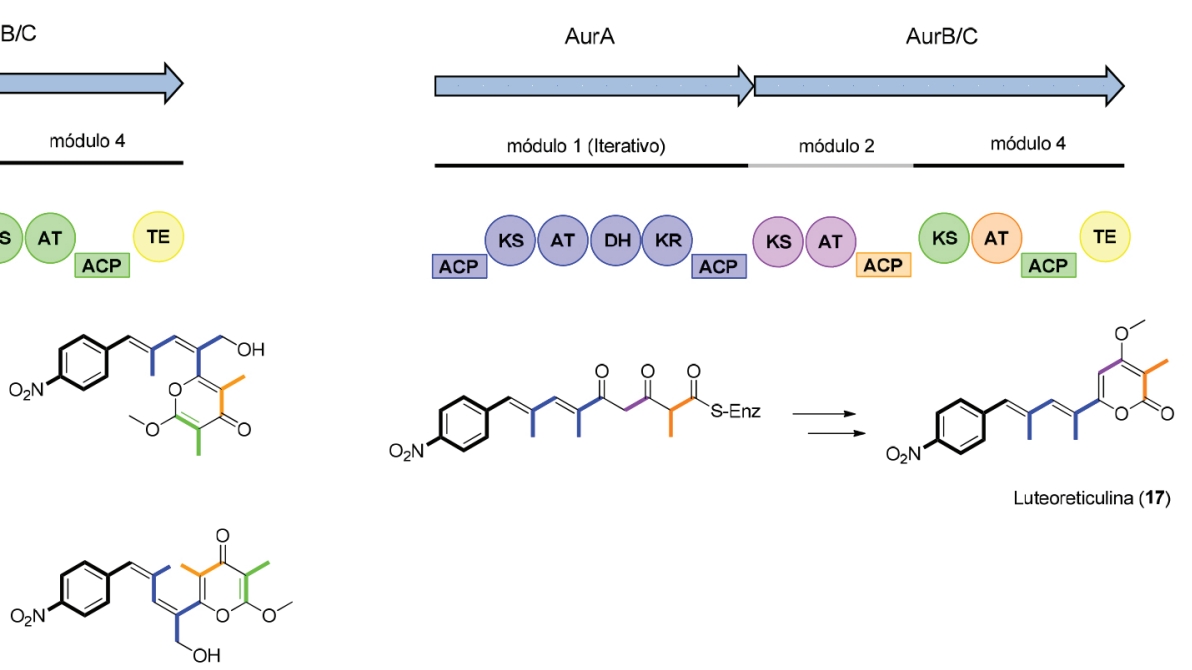

Luteoreticulina (17) 
plataforma online que organiza e classifica inúmeros espectros de MS/ MS de diferentes fontes, além de possibilitar o compartilhamento e comparação desses dados. O uso das ferramentas de desreplicação (MS/MS) auxiliam na obtenção de um conhecimento prévio do perfil do metabolismo secundário por comparação aos espectros de entidades já depositadas (Figura 7B). Nessa plataforma, o cientista solicitante envia os espectros de suas análises e o programa é capaz de comparar semelhanças no perfil de fragmentação. Para alimentar a base com novos produtos naturais, o cientista solicitante deposita o espectro de MS/MS, realiza a anotação e uma parcela da comunidade avalia a acurácia dos dados obtidos e os novos produtos são integrados à plataforma. Na última atualização publicada haviam mais de 18 mil compostos com alta acurácia (classificados como ouro) no banco de dados principal, enquanto que o conjunto de dados públicos ultrapassava 220 mil (classificados como bronze).

Além disso, é disponibilizado o tratamento de dados por meio de uma rede molecular (molecular networking). ${ }^{37}$ Nessa aplicação os dados de MS/MS são categorizados de acordo com suas perdas de massas relativas formando grupos de íons que apresentam, portanto, similaridade estrutural. Dessa forma, estruturas correlatas podem ser identificadas.

O potencial biossintético de microrganismos não cultiváveis em condições laboratoriais também tem sido explorado com o intuito de aumentar o arsenal desconhecido das policetídeos sintases. Estimase que seja necessário cultivar $10^{7}$ microrganismos para encontrar uma nova classe de metabólitos naturais bioativos ${ }^{38} \mathrm{e}$, portanto, as

A

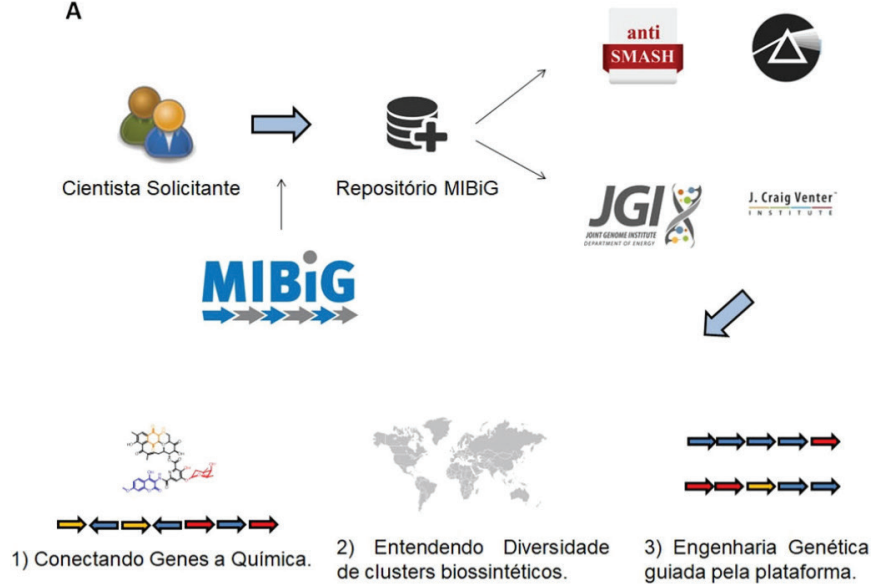

fontes não cultiváveis podem representar uma interessante reserva de diversidade estrutural ainda não explorada. ${ }^{39,40}$

Existem diversos meios de acessar as sequências codificadas em microrganismos não cultiváveis em laboratórios. A clonagem de grandes fragmentos de DNA, por exemplo, possibilita o acesso das sequências totais de um determinado nicho biológico. O metagenoma ("genoma total") facilita o acesso às moléculas biossintetizadas por organismos não cultiváveis em laboratório. As bibliotecas de grandes fragmentos de DNA são transferidas para microrganismos cultiváveis, como Escherichia coli e podem ser mais facilmente replicadas e triadas seguindo metodologias classificadas em 2 categorias: 1) baseadas em sequência; ou 2) baseadas em funções. Como o nome sugere, a categoria baseada em sequência depende da triagem da biblioteca metagenômica por homologia a sequência genética de interesse, facilitando a identificação de clusters biossintéticos. Nos métodos baseados em função, a triagem dos clones é realizada a partir de uma função de interesse, como atividade antibiótica, transformação bioquímica ou etapa biocatalítica. Após identificado o recombinante de interesse, a informação genética pode ser transferida para outros organismos heterólogos e estudada com maior profundidade. Geralmente, é realizada a transformação em actinobactérias que apresentam algumas vantagens em relação a organismos mais simples, como a presença de blocos de biossíntese essenciais para que PKSs sejam ativadas (Figura 8).

Os policetídeos nosperina $(\mathbf{1 9})^{41}$ e arimetamicinas $(\mathbf{2 0}$ e $\mathbf{2 1}),{ }^{42}$ isolados de organismos do solo, e o sideróforo vibrioferrina (22), ${ }^{43}$

B

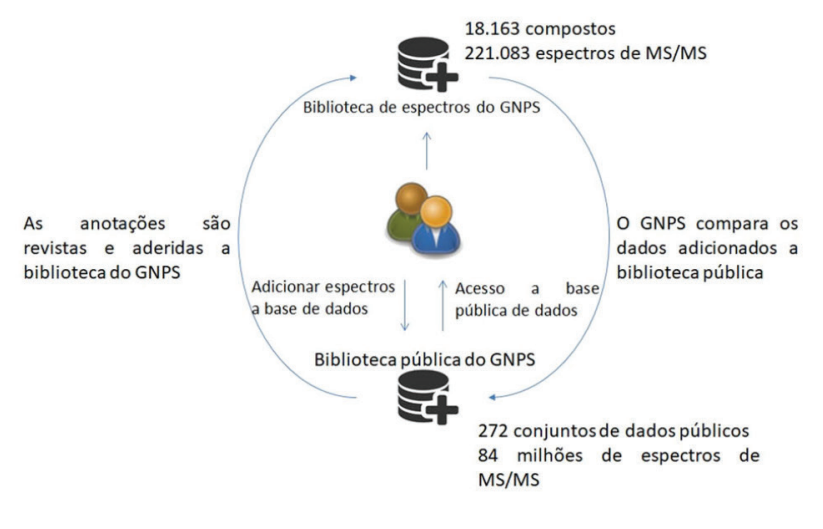

Figura 7. Visão geral das funções dos programas voltados ao armazenamento de dados genéticos e do GNPS respectivamente
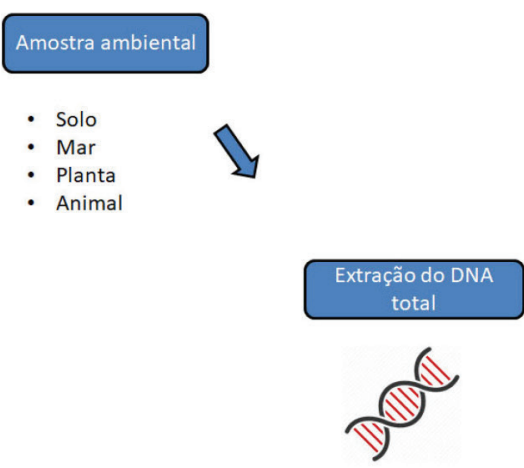

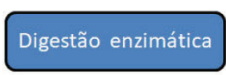

- Enzima de restrição

- Fragmentos entre $90-100 \mathrm{~kb}$

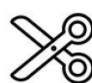

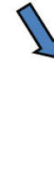
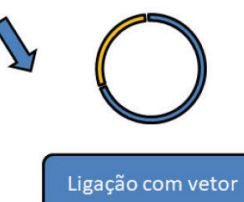

- Cosmídeo

- BAC (Bacterial Artificial Chromossome)
Triagem da biblioteca

- Triagem guiada por sequência

- Triagem guiada pela função

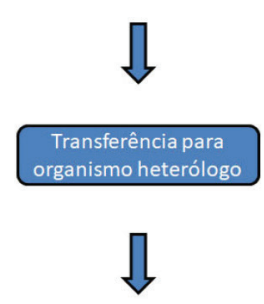


oriundos de ecossistemas marinhos, são exemplos de metabólitos isolados por exploração do metagenoma (Figura 9).

\section{ESTRATÉGIAS DE ENGENHARIA GENÉTICA EM POLICETÍDEOS}

Várias estratégias podem ser adotadas com o intuito de gerar diversidade estrutural utilizando-se da colinearidade observada entre gene, proteína e produto policetídico obtido ao longo da biossíntese. É possível alterar a ordem dos domínios e módulos funcionais das PKS, a estereoquímica (KR), manipular o nível de oxidação do carbono da subunidade condensada (KR, DH, ER), o comprimento da cadeia policetídica e ainda promover a incorporação de substratos diferentes da via policetídica natural (AT). ${ }^{44,45}$ Muitas das modificações pós-traducionais, podem também ser manipuladas, retirando-as da biossíntese ou modificando elementos já presentes. Geralmente, essas transformações envolvem glicosilações ${ }^{46}$ ou prenilações ${ }^{47}$ e não se apresentam em linha com a PKS. Muitas enzimas pós-traducionais são testadas também quanto a promiscuidade dos substratos para utilização em biocatálise e são capazes de gerar novos produtos naturais. ${ }^{48}$

Uma metodologia final que pode ser adicionada para gerar diversidade estrutural é denominada mutassíntese. Nesse sistema a engenharia genética é utilizada para manipular as PKSs e torná-las hábeis a interagir com a química orgânica sintética. ${ }^{49}$ Essa estratégia é baseada na alteração de uma pequena porção da via biossintética, seja pelo aumento da promiscuidade de uma enzima envolvida na incorporação de um precursor (AT), ou pela modificação de um domínio de cetosintase (KS). A modificação genética para promover inserção de unidades não naturais tem sido alvo de estudos para gerar estruturas não naturais na biossíntese de policetídeos. Vale ressaltar que essas modificações devem ser minimamente invasivas para que o módulo em questão não perca a sua função e interrompa a produção por completo. ${ }^{50}$ Um exemplo de modificação bem-sucedida resultou na obtenção de análogos propargilados da eritromicina. Auxiliado pelo docking molecular, foi observado que um resíduo de valina presente na AT do sexto módulo poderia ser modificado para aumentar sua aceitação por diferentes substratos. O mutante (Val295Ala) foi

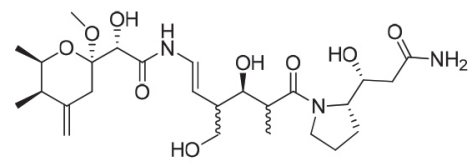

Nosperina (19)

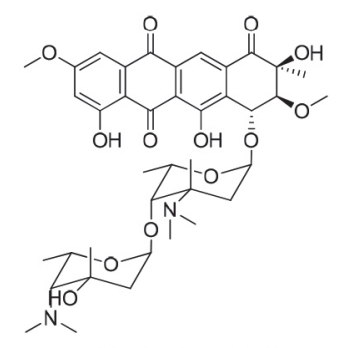

Arimetamicina A (20) capaz de incorporar o substrato não natural 2-propargilmalonil-SNAC e produzir 2-propargileritromicina A (23). ${ }^{51}$

No passado, o termo mutassíntese se referia a promoção de diversidade estrutural simplesmente pela oferta de precursores semelhantes aos originais, explorando a promiscuidade das PKSs. ${ }^{52}$ Como exemplo, o domínio AT do módulo 4 do imunossupressor FK506 (24) aceita naturalmente resíduos de metilmalonil-, etilmalonil-, propilmalonil- e alilmalonil-CoA, assim como, derivados dessas estruturas aciladas, que podem ser suplementadas ao meio de cultivo. O uso desses precursores modificados tem levado ao isolamento de estruturas com atividade imunossupressora mais elevada em comparação ao produto natural (Figura 10). ${ }^{53}$

\section{PLANEJAMENTO E USO DO ORGANISMO NATIVO OU HETERÓLOGO}

Antes de entender como são realizadas as manipulações genéticas para gerar diversidade em PKSs, devemos considerar alguns aspectos relevantes que auxiliam na modificação desses sistemas. Ao planejar uma manipulação genética devemos questionar o uso do organismo nativo como alvo da modificação ou, também, o uso de um organismo heterólogo.

A vantagem de se utilizar o organismo nativo é que a sequência completa da PKS está presente e intacta para a modificação. Não é necessário isolar o cluster biossintético e despender esforços para transferi-lo a outro organismo capaz de traduzir a sequência desejada. Além disso, o detentor da PKS geralmente apresenta todos os elementos necessários para expressar funcionalmente essas sintases, carregando, por exemplo, os principais blocos de construção dos policetídeos e grupos prostéticos necessários para ativar as enzimas (holo-forma), como a fosfopanteteína (reação catalisada pela fosfopanteteína transferase Ppant). ${ }^{54}$

Já os organismos heterólogos visam suprir alguma necessidade que o nativo não possui ou é debilitado. Por exemplo, existem organismos portadores das PKSs que apresentam ciclos de crescimento longos, produzem metabólitos em baixas concentrações, apresentam condições de preparo difíceis, não são cultiváveis em laboratório (metagenômica) ou o cluster de interesse encontra-se silenciado,
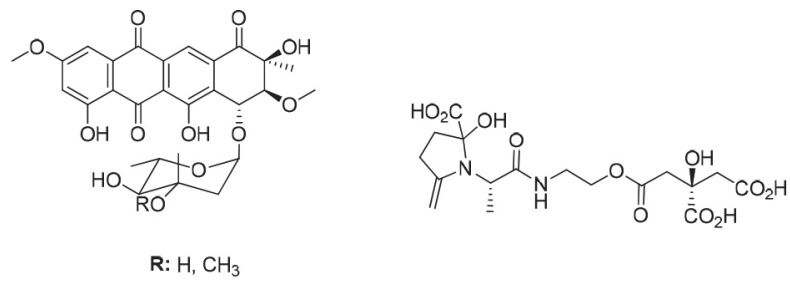

Vibrioferrina (22)

Figura 9. Estrutura química dos metabólitos guiados pela metodologia de metagenômica

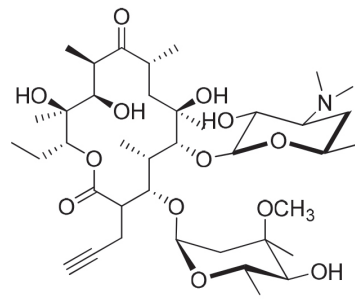

2-propargileritromicina (23)

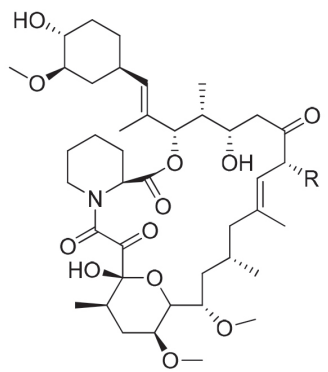

FK-506 (24)

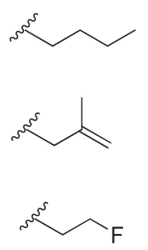

$\overbrace{F}$

Figura 10. Estruturas de policetídeos obtidas por mutassíntese 
tornando a expressão em heterólogo uma alternativa atraente.

Além disso, o uso de organismos heterólogos pode oferecer algumas vantagens, como a presença de promotores induzíveis, metabolismo secundário de algumas vias de biossíntese silenciados (o que auxilia na identificação do metabólito) e pode ainda possuir indutores globais de biossíntese. Ambas as estratégias de modificação, tanto em organismo nativo quanto em heterólogo, são baseadas nos sistemas de recombinação dos bacteriófagos ${ }^{55}$ e a escolha pelo organismo ideal para engenharia genética são ditadas basicamente pelas características do organismo nativo.

\section{Engenharia genética no organismo nativo}

A maioria das modificações realizadas nos organismos nativos utiliza-se dos eventos de recombinação homóloga para gerar mutações. Usualmente, ela é realizada a partir de um duplo crossover que consiste na construção de um vetor "suicida" que apresenta regiões de homologia com a sequência desejada (podendo ser incorporado entre elas deleções, substituição de sequências ou inserções) e não possui origem de replicação no organismo nativo, tornando-o instável na ausência de um marcador de resistência específico (normalmente é utilizado a resistência a algum antibiótico ou a temperatura). $\mathrm{O}$ vetor também possui sítios de integração (int, derivados do sítio фC31 do fago) ao genoma do organismo nativo em sítios específicos de reconhecimento $(a t t P) .^{56}$

O microrganismo depende de dois eventos distintos, o primeiro envolve a inserção do fragmento de DNA mediado pela integrase C31 e mantido através do marcador de resistência e o segundo evento ocorre na ausência do marcador, que inutiliza o segmento por conta da ausência da origem de replicação. Nesse caso, o microrganismo pode retornar a linhagem selvagem ou então pode incorporar a mutação envolvendo o uso da recombinase (Cre e FLP), ${ }^{55}$ que reconhece as regiões de homologia inseridas e promove a substituição dos genes, levando ao organismo modificado (Figura 11). Essa metodologia é aplicada principalmente em actinobactérias, para as quais esses elementos foram amplamente estudados. As restrições encontram-se na modificação de fragmentos maiores que $15 \mathrm{kbp}$.

Metodologias mais modernas de edição de genomas como o sistema CRISPR/Cas9 (Clustered Regularly Interspaced Short Palindromic Repeats) também podem auxiliar na biossíntese combinatória, facilitando modificações por deleções genéticas, alterações de sequências e inserções de genes. O CRISPR/Cas9 é uma ferramenta baseada em um antigo mecanismo de defesa natural encontrado nas bactérias para proteger seu conteúdo genético de DNA exógeno. ${ }^{57}$ Esse mecanismo consiste em um agrupamento de repetições palindrômicas curtas, regularmente interespaçadas, que mantém próximas sequências reconhecidas pela endonuclease denominada Cas9. ${ }^{58,59}$

Especificamente, à medida que a região palindrômica é preenchida com DNA viral, ela se torna um acessório para atacar o vírus, pois o microrganismo pode traduzir o material genético em cada espaçador (crRNA - CRISPR RNAs) e formar o complexo Cas9crRNA-tracRNA (trans-activating crRNA e trans-encoded RNA) que desliza sobre o DNA viral. A formação do híbrido crRNA-tracRNA guia a endonuclease Cas9 que hidrolisa o DNA exógeno, impedindo a replicação do vírus.

Evidências recentes revelam que a clivagem do DNA ocorre na presença de um pequeno segmento viral (protospacer) próximo a região 3' do DNA de interesse (NGG - N qualquer base, seguido de 2 guaninas). Essa pequena sequência, denominada PAM, permite o uso do sistema CRISPR/Cas9 nos mais variados organismos, como células humanas, ${ }^{60}$ S. cerevisiae,${ }^{61}$ E. coli ${ }^{62}$ e diferentes espécies de Streptomyces,${ }^{63}$ possibilitando qualquer mutação direcionada a partir da informação inserida entre os espaçadores do sistema CRISPR/ Cas9. Ao passo que a clivagem é realizada pela Cas9, a polimerase reparadora reconstrói a clivagem podendo ser inserido pequenas mutações na sequência (Figura 12). Existe também a possibilidade de

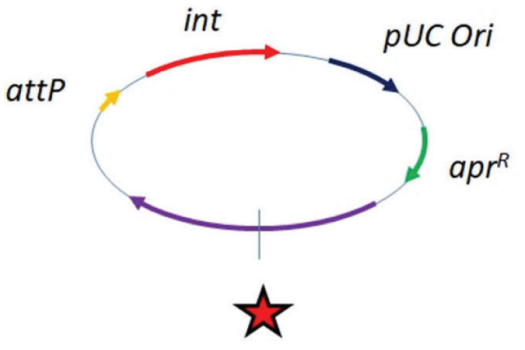

Região desejada com mutação

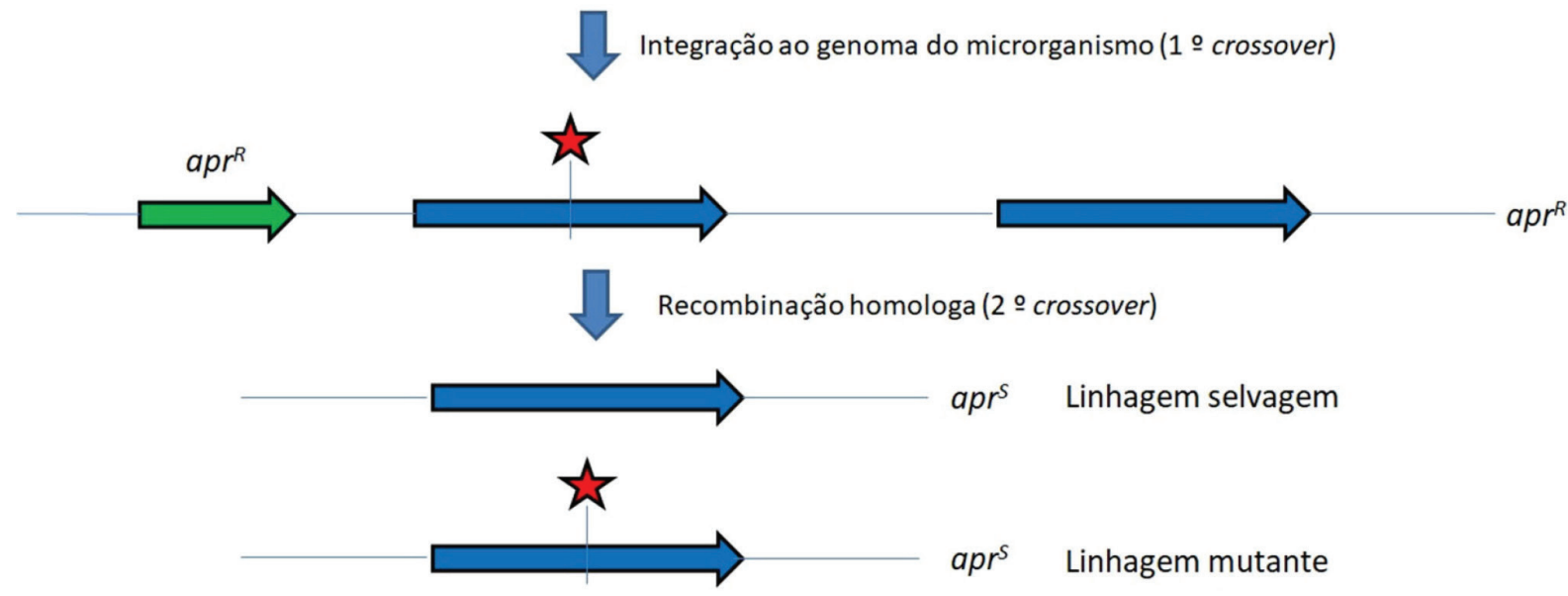

Figura 11. Visão geral sobre a manipulação genética de microrganismos nativos utilizando o duplo "crossover" 
inserir um DNA molde que compartilhe homologia com a sequência clivada. O resultado dessa etapa, viabiliza a edição desse fragmento a partir da recombinação homóloga.

Esse sistema tem sido eficientemente aplicado para ativar clusters biossintéticos em diversas linhagens de Streptomyces. Além disso, através do seu uso foi possível adicionar alguns promotores de biossíntese ( $\mathrm{ermp}^{*}$ e $k a s O^{*} \mathrm{p}$ ), levando a produção de novos policetídeos aromáticos do tipo II em Streptomyces viridochromogenes. ${ }^{64}$

\section{Engenharia genética em organismo heterólogo}

Os avanços recentes em biologia sintética possibilitam aos químicos de produtos naturais montar e reorganizar grandes clusters de genes biossintéticos de maneira rápida e precisa,${ }^{65}$ além de viabilizar uma série de organismos otimizados para a expressão heteróloga. Esses avanços proporcionam tanto o incremento da produção de um determinado produto natural como gerar diversidade estrutural. Métodos baseados em ligação de sequências homólogas têm sido extensivamente utilizados para a montagem de grandes fragmentos de DNA e clonagem em uma única etapa de clusters biossintéticos. ${ }^{66,67}$

A recombinação Red/ET (exonuclease/polimerase) consiste em uma metodologia de pareamento de regiões homólogas realizado in vivo por uma $E$. coli que contem os genes que codificam para o sistema de recombinação dos fagos, Red $\alpha / \operatorname{Red} \beta$. Esse sistema é utilizado para recombinar um vetor circular e um fragmento linear, transformados em E. coli (Linear-plus-Circular Homologous Recombination, LCHR). O resultado desse processo é um plasmídeo circular que carrega o cluster de interesse proveniente do DNA genômico e um marcador de resistência (antibiótico) que pode ser facilmente selecionado. ${ }^{68,69}$ Idealmente, o vetor pode conter as informações necessárias para a integração ao sistema do organismo heterólogo e se tornar funcional para a expressão das vias biossintéticas. Red/ET foi utilizado com sucesso na definição dos genes essenciais para a biossíntese de asukamicinas (25) em Streptomyces nodosus (subsp. asukaensis) ${ }^{70}$ e da fostriecina (26) de Streptomyces pulveraceus. ${ }^{71}$

Apesar do sucesso em reconstruir grandes clusters biossínteticos para expressão heteróloga, o sistema de recombinação Red/ET falha quando é necessário associar mais de um fragmento devido a contínua necessidade de adicionar um marcador de resistência. Mais recentemente foi relatada uma variante dessa metodologia, utilizando o sistema RecE/RecT em sua composição completa. Esse sistema é utilizado para a recombinação homóloga de fragmentos lineares (Linear-Linear Homologous Recombination, LLHR) que apresentam regiões flanqueadoras homólogas. ${ }^{72} \mathrm{O}$ LLHR é mediado por um sistema de recombinação derivado do prófago RAC, composto por RecE (exonuclease), RecT (DNA polimerase - fita única), RecA (proteína reparadora - corrige erros de sequência) e Rec $\gamma$ (inibidor de RecE).

Um procedimento convencional para utilizar esse sistema consiste na digestão do DNA genômico (sem clivar a região de interesse) e adicionar o vetor contendo regiões flanqueadoras nas extremidades (amplificado por PCR) em uma transformação única em E. coli. O sistema RecE/RecT irá parear as regiões homólogas e ligar ao vetor linear. Esse novo plasmídeo carreador do cluster desejado pode ser transferido para organismo heterólogo para avaliar a produção, além de possibilitar manipulações, como deleções, inserções e substituições genéticas. Essa metodologia possibilitou a clonagem direta do cluster responsável pela biossíntese dos policetídeos luminamicina A (27) e do peptídeo não ribossomal luminamida (28), produzidos por Photorhabdus luminescens (Figura 14). ${ }^{72}$

Embora o LLHR permita eficientemente a clonagem direta de um cluster biossintético a partir do DNA genômico, a eficácia dessa metodologia é limitada pelo tamanho do fragmento a ser clonado, sendo necessário, eventualmente, a divisão do cluster em fragmentos ou realizar a ligação em várias etapas. Para a reconstituição da biossíntese da salinomicina (6) (106 kbp) foram necessárias três etapas de recombinação para posterior expressão em Streptomyces coelicolor $\mathrm{A} 3 .^{73}$

Adicionalmente, metodologias que permitem a recombinação de fragmentos maiores têm sido desenvolvidas para suprir as necessidades de clonar grandes clusters biossintéticos. Nesse sentido a recombinação associada a transformação (TAR) é uma metodologia desenvolvida no início dos anos 90, mas que foi sendo aprimorada durante os anos, permitindo a recombinação de até $250 \mathrm{kbp}$ de informação. ${ }^{74}$ A metodologia TAR utiliza a levedura Saccharomyces cerevisiae que possui seu próprio maquinário para promover recombinação in vivo de fragmentos, tornando-se uma alternativa aos sistemas bacterianos.

Devido a robustez para grandes fragmentos, essa metodologia foi associada inicialmente a metagenômica para remontar clones de cosmídeos com regiões de sobreposição, levando a adutos de biossíntese mais sofisticados como as fluostatinas F, G e $\mathrm{H} \mathrm{(29)})^{75}$ e a rabelomicina (30), ${ }^{76}$ e um pentaciclo (31) derivado de uma PKS do tipo II, produzidos em organismo heterólogo, Streptomyces albus.

Novos vetores, como o pCAP01, ${ }^{77}$ foram desenvolvidos para utilização no sistema TAR e clonagem direta do DNA genômico. Esse novo vetor possui elementos de 3 hospedeiros: origem de replicação

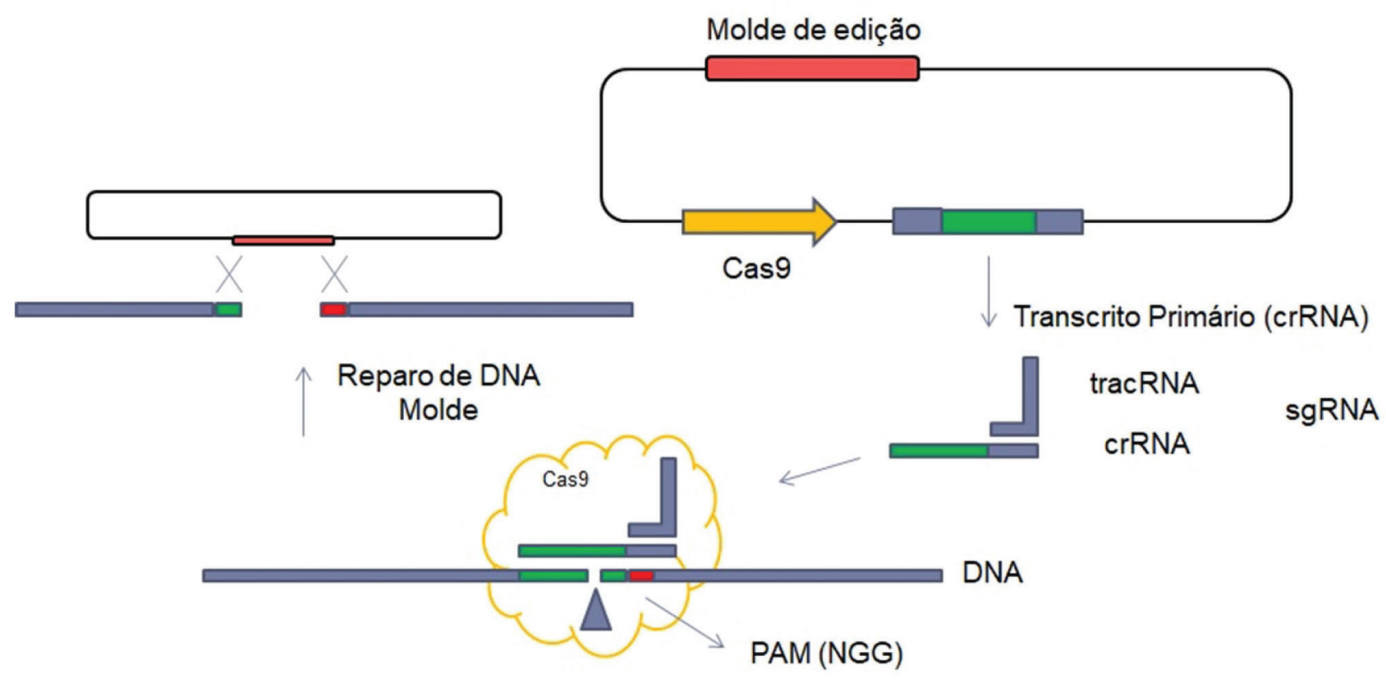

Figura 12. Mecanismo de operação do sistema CRISPR/Cas9 (single guide sgRNA) 
em S. cerevisiae (Arsh4/Cen6); origem de replicação em E. coli ( $p U C$ ori), baseada em cosmídeos para alta taxa de multiplicação e manutenção do vetor quando transferido para E. coli; e o sítio $\phi \mathrm{C} 31$ de integração ao genoma de actinobactérias (int e attp). Em alguns planejamentos é possível ainda integrar um promotor que direciona a produção de metabólitos secundários.

Adotando o vetor pCAP01 foi possível clonar e ativar o cluster biossintético (67 kbp) associado a produção do lipopeptídeo taromicina A presente na actinobactéria marinha Saccharomonospora sp. CNQ-490. Além desse metabólito, foi possível promover a biossíntese do marinopirrol (32) (30 kbp), utilizando como hospedeiro a Streptomyces coelicolor. ${ }^{78}$

O sistema de recombinação em leveduras também permite a construção de vetores a partir de vários fragmentos amplificados por PCR que compartilhem regiões de homologia entre si, o que possibilita a reconstrução completa de clusters biossintéticos, como é o caso da alpiniamida A (33) obtidas de Streptomyces sp. CBMAI 2042 (dado não publicado). Além disso é possível desenhar deleções e inserções de domínios, tornando o TAR uma metodologia aplicável para a biossíntese

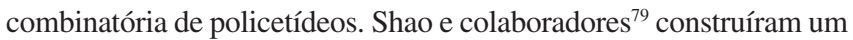
vetor via TAR para produzir os policetídeos do tipo I aurethina (11) e spectinabilina (34) (49 kb), de Streptomyces thiolatus. O plasmídeo de recombinação foi construído com base em 7 fragmentos amplificados por PCR e recombinados em S. cerevisiae. Além disso, foram realizadas modificações nos próprios primers de PCR para gerar mutações sítio-dirigidas. Adotando essa estratégia, a DH presente em AurB foi inativada pela construção do duplo mutante H964A/D1131A levando a produção do análogo hidroxilado (35, Figura 14).

Até o momento, todas as metodologias de recombinação apresentadas necessitam de um organismo vivo. Porém, existe um método muito bem consolidado que descarta a necessidade de um sistema vivo para realizar a recombinação resultando em um vetor circular. Esse método é conhecido como SLIC (Sequence Ligation Independent Cloning $)^{80,81}$ e pode ser realizado com kits comerciais baseados nas metodologias isotérmicas de Gibson ${ }^{82}$ (Gibson Assembly) e algumas variantes que executam as mesmas funções encontradas in vivo.

$\mathrm{O}$ vetor linear e os fragmentos obtidos via PCR ou restrição do genoma podem ser recombinados em uma reação isotérmica a $50^{\circ} \mathrm{C}$ baseada na ação de uma T5 exonuclease, que degrada a sequência de DNA na direção 3' - 5' gerando as terminações protuberantes 3' que podem reanelar por complementaridade a outra sequência. Uma DNA polimerase preenche as sequências restantes e a DNA ligase sela as regiões de ligação. Esse vetor construído é imediatamente transformado em E. coli para manutenção e preservação do mesmo, que posteriormente pode ser transferido para o organismo produtor. A vantagem de se utilizar esse sistema de recombinação em detrimento da ligação tradicional de fragmentos é a presença do braço de homologia que é criado capaz de estabilizar a recombinação de grandes fragmentos de DNA. ${ }^{82}$

A metodologia SLIC foi utilizada em biossíntese combinatória de policetídeos na obtenção de derivados da premonensina (36, Figura 14) ${ }^{83}$ Fragmentos amplificados por PCR carregando uma deleção foram ligados ao plasmídeo pKC1139 utilizando o SLIC-mix. Esse plasmídeo possui todos os elementos de integração ao genoma de Streptomyces (int e attP), uma origem de replicação sensível a temperatura (repT) e marcador de resistência a apramicina (apr). Em um primeiro evento, o plasmídeo foi adicionado a Streptomyces cinnamonensis e as linhagens resistentes a apramicina selecionadas. Posteriormente, essas colônias foram cultivadas a $40^{\circ} \mathrm{C}$ para favorecer o segundo evento de recombinação, no qual o fragmento adicionado pode ser expulso (retornando a cepa nativa) ou incorporado por recombinação homóloga, originando a linhagem mutante. Utilizando essa metodologia de duplo crossover, foi possível manipular 22 derivados de premonensina com diferentes graus de redução na cadeia policetídica, sendo que alguns apresentaram um aumento de atividade antimicrobiana frente a Pseudomonas aeruginosa. ${ }^{83}$

Embora o sistema SLIC descarte o uso de um sistema in vivo para a recombinação, muitos questionamentos foram levantados quanto ao tamanho de fragmento passível de ser clonado por essa metodologia. Um procedimento interessante descrito por Zhou e colaboradores $^{84}$ propõe a clonagem em uma única etapa de $41 \mathrm{kbp}$ do cluster biossintético responsável pela biossíntese de conglobatina (37), em Streptomyces conglobatus. O procedimento proposto, consiste na digestão do DNA genômico (HindIII e XhoI) e amplificação do vetor por PCR adicionando braços de homologia com as regiões terminais do cluster. A metodologia isotérmica de Gibson foi utilizada para reorganização in vitro e o plasmídeo resultante foi transformado em E. coli. Utilizando esse método foi possível construir e transferir esse cluster para Streptomyces coelicolor, sem a necessidade de amplificar por PCR o agrupamento de interesse. A Figura 13 apresenta uma visão geral das técnicas utilizadas para reconstrução e ampliação da diversidade estrutural em policetídeo sintases apresentadas nessa revisão.

\section{CONCLUSÕES E PERSPECTIVAS}

Os policetídeos representam umas das classes de produtos naturais mais promissoras para a descoberta de novos candidatos a fármacos. O repertório biossintético revela uma impressionante habilidade da natureza em produzir compostos estruturalmente sofisticados, a partir de estruturas simples, como o acetato. ${ }^{14}$

Com o intuito de aumentar a diversidade metabólica que megassintases como as PKSs, a engenharia genética evoluiu um conjunto de técnicas de manipulações para modificar os módulos e domínios enzimáticos presentes nessas enzimas, possibilitando a produção de um grande número de novas estruturas dirigidas pelo conhecimento em biossíntese.

Para a descoberta de novos fármacos, usualmente grandes bibliotecas de compostos são obtidas para triagem, mas no caso da aplicação de metodologias baseadas em biossíntese combinatória de produtos naturais não são produzidas bibliotecas numerosas, visto que as modificações são sempre guiadas. No entanto, vale ressaltar que a efetividade que essas estruturas apresentam reduz o tempo e o capital despendido, fatores bastante atrativos na prospecção de um candidato a fármaco.

Combinar a biossíntese e a química orgânica sintética permite ampliar ainda mais o arsenal de estruturas, tornando a área mais versátil devido a diferentes modificações que podem ser obtidas por reações enzimáticas. Adotar a biossíntese permite, por exemplo, ampliar o número de compostos com centros estereoquímicos altamente controlados e especializados para otimização da relação estrutura/ atividade biológica. Uma cooperação maior entre as duas áreas pode prover ferramentas que possibilitem a síntese de estruturas cada vez mais complexas, se comparado ao uso independente dos métodos.

Embora as pesquisas aqui demonstradas tenham uma orientação maior para a biossíntese de policetídeos, que por conta de sua organização modular facilitou até mesmo os primeiros estudos de biossíntese combinatória (amplamente executada no início dos anos 90), existe a possibilidade de gerar diversidade estrutural em todos os produtos naturais e isso representa um desafio recente para todos os que se relacionam com a área. Para isso, é necessário concentrar conhecimento em como manipular a informação genética das enzimas que catalisam a biossíntese dos produtos naturais. Nesse sentido, um dos pontos incide sobre a diversidade de sequências que conhecemos do metabolismo secundário. Quanto mais sequências conhecidas, mais substâncias podem ser descobertas e mais combinações podem 


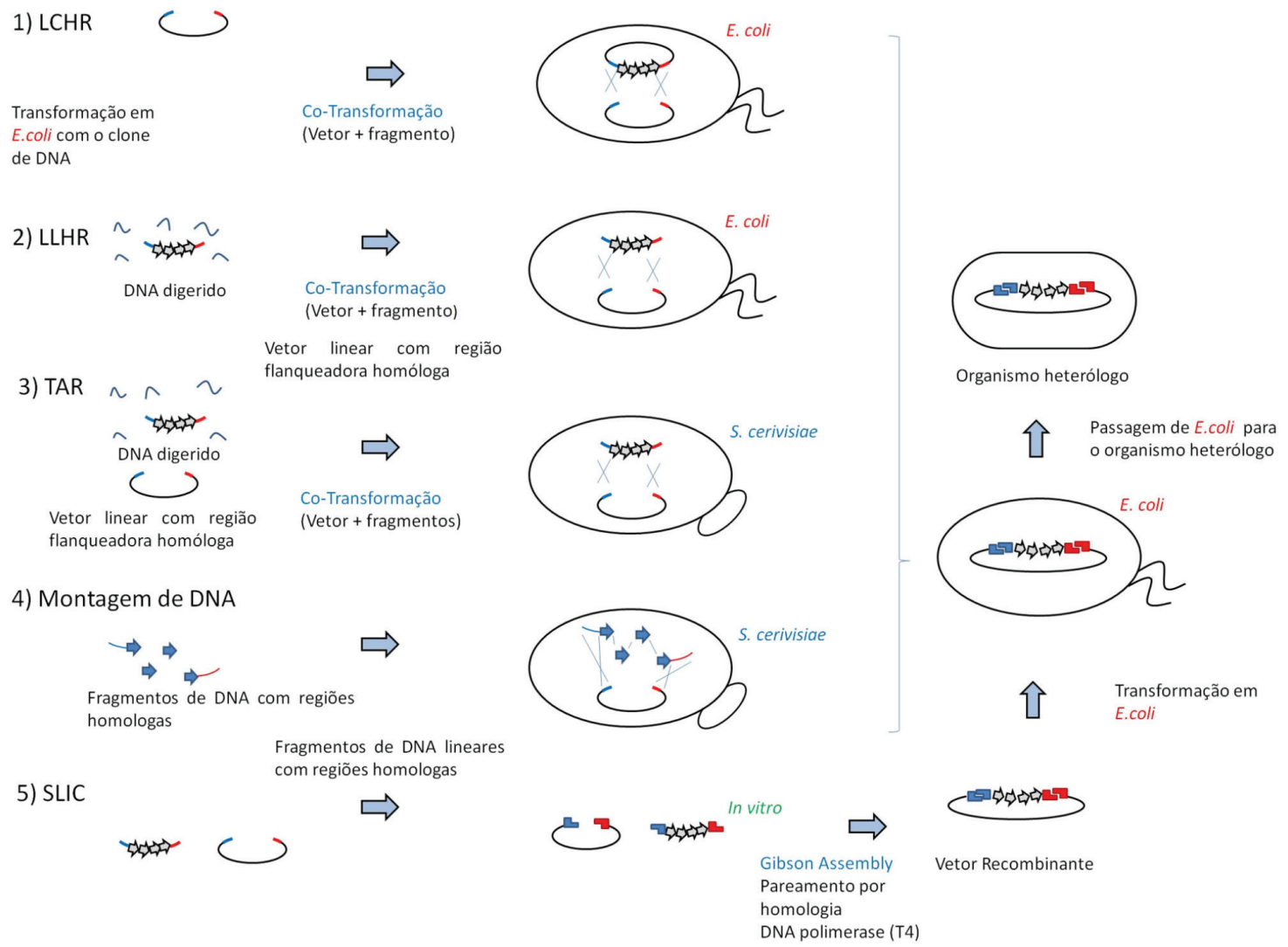

Figura 13. Metodologias de recombinação para clonagem de vias biossintéticas (adaptado de Kim e colaboradores) ${ }^{4}$

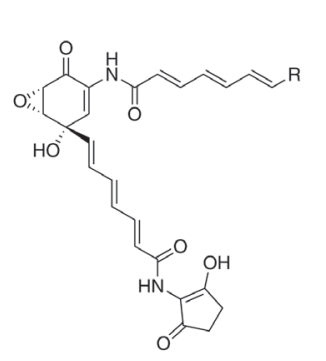

Asukamicinas (25)

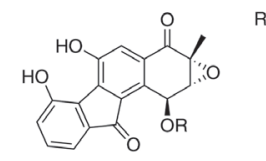

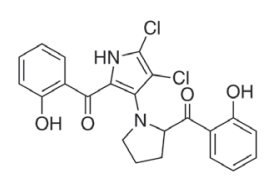

Marinopirrol (32)
R:

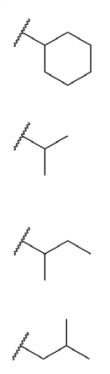

R: $\nvdash^{H}$ $\mathrm{CH}_{3}$

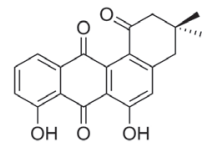

Rabelomicina (30)

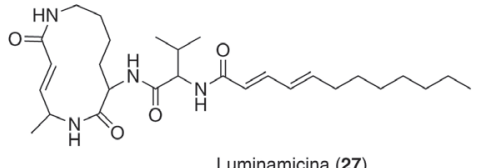

Fosfitriecina (26)

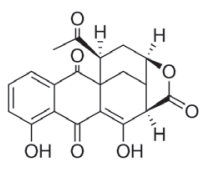

t2-PKS (31)

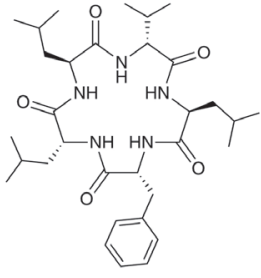

Luminamida (28)

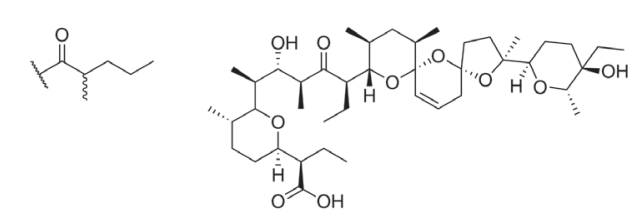

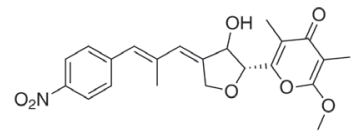<smiles>CCC=C(C)C(C)C(C)C(=O)CCC(=O)C(C)C(C)C(C)O</smiles>

Alpiniamida A (33)

Aurethina-OH (35)

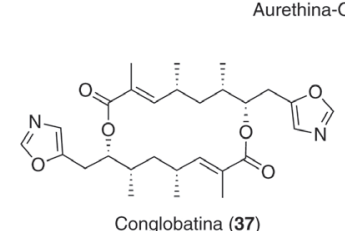

Conglobatina (37)

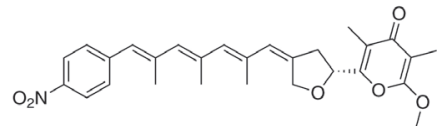

Spectinabilina (34)

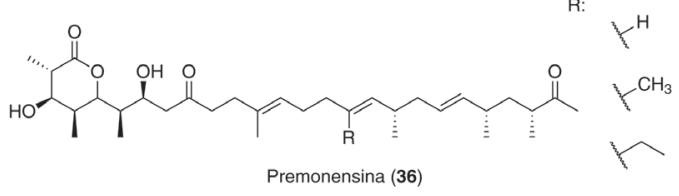

Figura 14. Estruturas de produtos naturais produzidos por expressão heteróloga ou manipulação de vias biossintética orientado principalmente para produção de policetídeos 
ser planejadas. Isso é um importante fator que tem impulsionado o uso de ferramentas de bioinformática e de metodologias (como o metagenoma e evolução dirigida) ${ }^{85}$

Um dos desafios remanescentes para a área, recai sobre a produção desses metabólitos modificados por biossíntese combinatória em escala industrial. A maior parte dos metabólitos produzidos por biossíntese combinatória sofre de baixa produtividade, sendo que para um fármaco ser autorizado e comercializado é necessário utilizar uma quantidade considerável do composto para testes clínicos. Nesse sentido, muitos avanços foram alcançados no desenvolvimento de promotores $^{86,87}$ e sítios de ligação do ribossomo. ${ }^{88}$

Algumas aplicações em técnicas conhecidas como chem-bio-chem surgiram para demonstrar que muitos esqueletos complexos podem ser derivatizados da natureza para tornar o processo factível. Um exemplo disso, é o antimalárico artemesinina produzido nas cascas de Artemesia annua. Em 2010 aproximadamente 655.000 mil mortes eram contabilizadas por conta da malária, sendo que o único fármaco altamente eficaz para o tratamento era produzido apenas em pequenas quantidades pela planta e a rota sintética era muito dispendiosa. A solução encontrada, foi transferir e aprimorar toda biossíntese do ácido artemesínico (intermediário) em S. cerivisiae. A partir desse precursor avançado o número de rotas sintéticas caiu drasticamente e a produção em larga escala do fármaco foi viabilizada. ${ }^{89}$

Com relação a biologia sintética, alcançamos um patamar em que várias alternativas podem ser adotadas, cada uma com um tipo diferente de limitação, cabe ao cientista ponderar qual aplicação é propícia para seu objetivo. Além disso, existem outras metodologias promissoras que estão começando a ser aderidas, como é o caso da técnica de edição de genomas utilizando o sistema CRISPR/Cas9, o que aumenta ainda mais a pletora de ferramentas que possuímos para manipular as sequências presentes nas enzimas.

O campo de biossíntese combinatória está pronto para novos desafios, onde o objetivo mais marcante é que o uso das sequências biossintéticas permite ao químico de produtos naturais influir sobre a natureza de suas estruturas.

\section{AGRADECIMENTOS}

Os autores expressam agradecimentos à FAPESP (2014/12727-5 e 2014/50249-8 (L.G.O); 2013/12598-8 e 2015/01013-4 (R.S.)) e ao CNPq (140824/2017-0 (B.S.P.) e 313492/2017-4 (LGO)).

\section{REFERÊNCIAS}

1. Bérdy, J.; J. Antibiot. 2012, 58, 385.

2. Bérdy, J.; J. Antibiot. 2005, $58,1$.

3. Newman, D. J.; Cragg, G. M.; J. Nat. Prod. 2016, 79, 629.

4. Kim, E.; Moore, B. S.; Yoon, Y. J.; Nat. Chem. Biol. 2015, 11, 649.

5. Goswami, S.; Vidyarthi, A. S.; Bhunia, B.; Mandal, T.; J. Biochem. Technol. 2012, 4, 581 .

6. Jeli, D.; Antolovic, R.; Antibiotics 2016, 5, 1 .

7. Lewis, R. E.; Kontoyiannis, D. P.; Darouiche, R. O.; Raad, I. I.; Prince, R. A.; Antimicrob. Agents. Chemother. 2002, 46, 3499.

8. Lim, L. E.; Vilchèze, C.; Carol, N G.; Jacobs, W. R.; Santiago, R. G.; Thompson, J.; Antimicrob. Agents. Chemother. 2013, 57, 1040.

9. Patel, J. M.; J. Mol. Catal. B: Enzym. 2009, 61, 123.

10. Zhou, S.; Wang, F.; Wong, E. T.; Fonkem, E.; Hsieh, T. C.; Wu, J. M.; Wu, E.; Curr. Med. Chem. 2013, 20, 4095.

11. Luo, Y.; Cobb, R. E.; Zhao, H.; Curr. Opin. Biotechnol. 2014, 30, 230.

12. Hopwood, D. A.; Malpartida, F.; Kieser, H. M.; Ikeda, H.; Duncan, J.; Fujii, I.; Rudd, B. A. M.; Floss, H. G.; Omura, S.; Nature 1985, 314, 642.

13. Smith, S.; Tsai, S. C.; Nat. Prod. Rep. 2007, 24, 1041.
14. Hertweck, C.; Angew. Chem. 2009, 48, 4688.

15. Dewick, P. M.; Medicinal Natural Products A biosynthetic approach, $3^{\text {rd }}$ ed., Wiley: Nottingham, 2009.

16. Shen, B.; Curr. Opin. Chem. Biol. 2003, 7, 285.

17. Cortés, J. Velasco, J.; Foster, G.; Blackaby, A. P.; Rudd, B. A. M.; Wilkinson, B.; Mol. Microbiol. 2002, 44, 1213.

18. Fu, C.; Auerbach, D.; Li, Y.; Scheid, U.; Luxenburger, E.; Garcia, R.; Irschik, H.; Rolf, M.; Angew. Chem. 2017, 56, 2192.

19. Cortes, J.; Haydock, S. F.; Roberts, G. A.; Bevitt, D. J.; Leadlay, P. F.; Nature 1990, 348, 176.

20. Donadio, S.; Staver, M. J.; McAlpine, J. B.; Swanson, S. J.; Katz, L.; Science 1991, 252, 675.

21. Cortes, J.; Wiesmann, K. E.; Roberts, G. A.; Brown, M. J.; Staunton, J.; Leadlay, P. F.; Science 1995, 268, 1487.

22. Kao, C. M.; Khosla, C.; Luo, G.; Cane, D. E.; Katz, L.; J. Am. Chem. Soc. 1995, 117, 9105.

23. Oliynyk, M.; Brown, M. J. B.; Cortes, J.; Staunton, J.; Leadlay, P. F.; Chem. Biol. 1996, 3, 833.

24. McDaniel, R.; Ebert, K. S.; Hopwood, D. A.; Khosla, C.; Science 1993, $262,1546$.

25. Sugimoto, Y.; Ding, L.; Ishida, K.; Hertweck, C.; Angew. Chem. 2014, 53,1560

26. Wong, F. T.; Khosla, C.; Curr. Opin. Chem. Biol. 2012, 16, 117.

27. Bentley, S. D.; Chater, K. F.; Cerdeno, T. A. M.; Challis, G. L.; Thomson, N. R.; James, K. D.; Harris, D. E.; Quail, M. A.; Kieser, H.; Harper, D.; Bateman, A.; Brown, S.; Chandra, G.; Chen, C. W.; Collins, M.; Cronin, A.; Fraser, A.; Goble, A.; Hidalgo, J.; Hornsby, T.; Howarth, S.; Huang, C. H.; Kieser, T.; Larke, L.; Murphy, L.; Oliver, K.; O’Neil, S.; Rabbinowitsch, E.; Rajandream, M. A.; Rutherford, K.; Rutter, S.; Seeger, K.; Saunders, D.; Sharp, S.; Squares, R.; Squares, S.; Taylor, K.; Warren, T.; Wietzorrek, A.; Woodward, J.; Barrell, B. G.; Parkhill, J.; Hopwood, D. A.; Nature 2002, 417, 141

28. De Oliveira, L. G.; Pupo, M. T.; Vieira, P. C.; Quim. Nova 2013, 36, 1577.

29. Zotchev, S. B.; Sekurova, O. N.; Katz, L.; Curr. Opin. Biotechnol. 2012, 23, 941

30. Piel, J.; Nat. Prod. Rep. 2010, 27, 996.

31. Medema, M. H.; Raaphorst, R. V.; Takano, E.; Breitling, R.; Nat. Microbiol. 2012, 10, 191.

32. Weber, T.; Blin, K.; Duddela, S.; Krug, D.; Kim, H. U.; Bruccoleri, R.; Lee, S. Y.; Fischbach, M. A.; Muller, R.; Wohlleben, W.; Breitling, R.; Takano, E.; Medema, M. H.; Nucleic. Acids. Res. 2015, 43, 1.

33. Khaldi, N. Seifuddin, F. T.; Turner, G.; Haft, D.; Nierman, W. C.; Wolfe, K. H.; Fedorova, N. D.; Fungal Genet. Biol. 2010, 47, 736.

34. Skinnider, M. A.; Dejong, C. A.; Rees, P. N.; Johnston, C. W.; Li, H.; Webster, A. L. H.; Wyatt, M. A.; Magarvey, N. A.; Nucleic Acids Res. 2015, 43, 9645.

35. Dejong, C. A. Chen, G. M.; Li, H.; Johnston, C. W.; Edwards, M. R.; Rees, P. N.; Skinnider, M. A.; Webster, A. L. H.; Magarvey, N. A.; Nat. Chem. Biol. 2016, 12, 1007.

36. Wang, M. Jeremy J.; Phelan, V. V.; Sanchez, L. M.; Garg, N.; Peng, Y.; Nguyen, D. Duy.; Watrous, J.; Kapono, C. A.; Luzzatto, K. T.; Porto, C.; Bouslimani, A.; Melnik, A. V.; Meehan, M. J.; Liu, W. T.; Crüsemann, M.; Boudreau, P. D.; Esquenazi, E.; Sandoval, C. M.; Kersten, R. D.; Pace, L. A.; Quinn, R. A.; Duncan, K. R.; Hsu, C. C.; Floros, D. J.; Gavilan, R. G.; Kleigrewe, K.; Northen, T.; Dutton, R. J.; Parrot, D.; Carlson, E. E.; Aigle, B.; Michelsen, C. F.; Jelsbak, L.; Sohlenkamp, C.; Pevzne, P.; Edlund, A.; McLean, J.; Piel, J.; Murphy, B. T.; Gerwick, L.; Liaw, C. C.; Yang, Y. L.; Humpf, H. U.; Maansson, M.; Keyzers, R. A.; Sims, A. C.; Johnson, A. R.; Sidebottom, A. M.; Sedio, B. E.; Klitgaard, A.; Larson, C. B.; Boya, C. A.; Torres, M. D.; Gonzalez, D. J.; Silva, D. B.; Marques, L. M.; Demarque, D. P.; Pociute, E.; O’Neill, E. C.; Briand, E.; Helfrich, E. J. N.; Granatosky, E. A.; Glukhov, E.; Ryffel, 
F.; Houson, H.; Mohimani, H.; Kharbush, J. J.; Zeng, Y.; Vorholt, J. A.; Kurita, K. L.; Charusanti, P.; McPhail, K. L.; Nielsen, K. Fog.; Vuong, L.; Elfeki, M.; Traxler, M. F.; Engene, N.; Koyama, N.; Vining, O. B.; Baric, R.; Silva, R. R.; Mascuch, S. J.; Tomasi, S.; Jenkins, S.; Macherla, V.; Hoffman, T.; Agarwal, V.; Williams, P. G.; Dai, J.; Neupane, R.; Gurr, J.; Rodríguez, A. M. C.; Lamsa, A.; Zhang, C.; Dorrestein, K.; Duggan, B. M.; Almaliti, J.; Allard, P. M.; Phapale, P.; Nothias, L. F.; Alexandrov, T.; Litaudon, M.; Wolfender, J. L.; Kyle, J. E.; Metz, T. O.; Peryea, T.; Nguyen, D. T.; VanLeer, D.; Shinn, P.; Jadhav, A.; Müller, R.; Waters, K. M.; Shi, W.; Liu, X.; Zhang, L.; Knight, R.; Jensen, P. R.; Palsson, B. Ø.; Pogliano, K.; Linington, R. G.; Gutiérrez, M.; Lopes, N. P.; Gerwick, W. H.; Moore, B. S.; Dorrestein, P. C.; Bandeira, N.; Nat. Biotechnol. 2016, $34,828$.

37. Yang, J. Y. Sanchez, L. M.; Rath, C. M.; Liu, X.; Boudreau, P. D.; Bruns, N.; J. Nat. Prod. 2013, 76, 1686.

38. Baltz, R. H.; Microbe 2007, 2, 125.

39. Stewart, E. J.; J. Bacteriol. 2012, 194, 4151.

40. Milshteyn, A.; Schneider, J. S.; Brady, S. F.; Chem. Biol. 2014, 21, 1211.

41. Kampa, A.; Gagunashvili, A. N.; Gulder, T. A. M.; Morinaka, B. I.; Daolio, C.; Godejohann, M.; Miao, V. P. W.; Piel, J.; Andrésson, Ó. S.; Proc. Natl. Acad. Sci. U. S. A. 2013, 110, 3129.

42. Kang, H.; Brady, S. F.; Angew. Chem. 2013, 52, 11063.

43. Fujita, M. J. Kimura, N.; Sakai, A.; Ichikawa, Y.; Hanyu, T.; Otsuka, M.; Ujita, M. J. F.; Imura, N. K.; Akai, A. S.; Chikawa, Y. I.; Biosci. Biotechnol. Biochem. 2011, 75, 2283.

44. Baerga-ortiz, A. Popovic, B.; Siskos, A. P.; Hare, H. M. O.; Spiteller, D.; Williams, M. G.; Campillo, N.; Spencer, J. B.; Leadlay, P. F.; Chem. Biol. 2006, 13, 277.

45. Li, Y.; Fiers, W. D.; Bernard, M.; Smith, J. L.; Aldrich, C. C.; Fecik, R. A.; ACS Chem. Biol. 2014, 9, 2914.

46. Nguyen, H. C.; Karray, F.; Lautru, S.; Gagnat, J.; Lebrihi, A.; Duong, T.; Huynh, H.; Pernodet, J. L.; Antimicrob. Agents. Chemother. 2010, 54, 2830.

47. Sanchez, J. F.; Entwistle, R.; Hung, J. H.; Yaegashi, J.; Chiang, Y.; Wang, C. C. C.; Oakley, B. R.; J. Am. Chem. Soc. 2011, 133, 4010.

48. Chooi, Y.; Wang, P.; Fang, J.; Li, Y.; Wu, K.; Wang, P.; Tang, Y.; J. Am. Chem. Soc. 2012, 134, 9428.

49. Weissman, K. J.; Trends. Biotechnol. 2007, 25, 139.

50. Floss, H. G.; J. Biotechnol. 2006, 124, 242.

51. Sanchez, G. E.; Schulz, F.; ACS Chem. Biol. 2013, 8, 443.

52. Cane, D. E.; Kudo, F.; Kinoshita, K.; Khosla, C.; Chem. Biol. 2002, 9, 131.

53. Mo, S.; Kim, O. D. H.; Lee, O. J. H.; Park, J. W.; Basnet, D. B.; Ban, Y. H.; Yoo, Y. J.; Chen, S. W.; Park, S. R.; Choi, E. A.; Kim, E.; Jin, Y. Y.; Lee, S. K.; Park, J. Y..; Liu, Y.; Lee, M. O.; Lee, K. S.; Kim, S. J.; Kim, D.; Park, C.; Lee, S. G.; Kwon, H. J.; Suh, J. W.; Moore, B. S.; Lim, S. K.; Yoon, Y. J.; J. Am. Chem. Soc. 2011, 133, 976.

54. Lambalot, R.; Gehring, A. M.; Fluge, R. S.; Zuber, P.; Lacelle, M.; Marahie, M. A.; Reid, R.; Khosia, C.; Walsh, C. T.; Chem. Biol. 1996, 3,923 .

55. Nafissi, N.; Slavcev, R.; Appl. Microbiol. Biotechnol. 2014, 98, 2841.

56. Sun, Y.; Hong, H.; Samboskyy, M.; Mironenko, T.; Leadlay, P. F.; Haydock, S. F.; Microbiology 2006, 152, 3507.

57. Deveau, H.; Garneau, J. E.; Moineau, S.; Annu. Rev. Microbiol. 2010, 64,475 .

58. Koonin, E. V.; Makarova, K. S.; RNA Biol. 2013, 10, 679.

59. Barrangou, R.; Marraffini, L. A.; Mol. Cell. 2014, 54, 234.
60. Cong, L.; Ran, F. A.; Cox, D.; Lin, S.; Barretto, R.; Habib, N.; Hsu, P. D.; Wu, X.; Jiang, W.; Science 2013, 339, 819.

61. Bao, Z. Xiao, H.; Liang, J.; Zhang, L.; Xiong, X.; Sun, N.; Si, T.; Zhao, H.; ACS Chem. Biol. 2015, 4, 585.

62. Jiang, W.; Bikard, D.; Cox, D.; Zhang, F.; Marraffini, L. A.; Nat. Biotechnol. 2013, 31, 233.

63. Cobb, R. E.; Wang, Y.; Zhao, H.; ACS Synth. Biol. 2015, 4, 723.

64. Zhang, M. M.; Wong, F. T.; Wang, Y.; Luo, S.; Lim, Y. H.; Heng, E.; Yeo, W. L.; Cobb, R. E.; Enghiad, B.; Ang, E. L.; Zhao, H.; Nat. Chem. Biol. 2017, 13, 607.

65. Editorial. Meeting Report for Synthetic Biology for Natural Products 2017: The Interface of (Meta)Genomics, Machine Learning, and Natural Product Discovery. ACS Synth. Biol. 2017, 6, 737.

66. Cobb, R. E.; Ning, J. C.; Zhao, H.; J. Ind. Microbiol. Biotechnol. 2014, $41,469$.

67. Gibson, D. G.; Nat. Methods 2014, 11, 521.

68. Zhang, Y.; Muyrers, J. P. P.; Stewart, A. F.; Nat. Biotechnol. 2000, 18, 1314.

69. Ongley, S. E.; Bian, X.; Neilan, B. A.; Muller, R.; Nat. Prod. Rep. 2013, 30, 1121.

70. Pospís, S.; Rui, Z.; Yang, Y.; Chen, C. Y.; Tsai, S. F.; Floss, H. G.; Petr, M.; J. Biol. Chem. 2010, 285, 24915.

71. Su, C. Zhao, X.; Qiu, R.; Tang, L.; Su, C.; Zhao, X.; Qiu, R.; Tang, L.; Pharm. Biol. 2015, 53, 269.

72. Fu, J.; Bian, X.; Hu, S.; Wang, H.; Huang, F.; Seibert, P. M.; Plaza, A.; Xia, L.; Müller, R.; Stewart, A. F.; Zhang, Y.; Nat. Biotechnol. 2012, 30, 440.

73. Yin, J.; Hoffmann, M.; Bian, X.; Tu, Q.; Yan, F.; Xia, L.; Nature 2015, 5,1 .

74. Kouprina, N.; Larionov, V.; Nature 2006, 7, 805.

75. Feng, Z.; Kim, J. H.; Brady, S. F.; J. Am. Chem. Soc. 2010, 132, 11902.

76. Feng, Z.; Kallifidas, D.; Brady, S. F.; Proc. Natl. Acad. Sci. U. S. A. 2011, 108, 12629.

77. Nah, H.; Pyeon, H. R.; Kang, S. H.; Choi, S. S.; Kim, E. S.; Kim, E. S.; Front. Microbiol. 2017, 8, 1.

78. Yamanaka, K.; Reynolds, K. A.; Kersten, R. D.; Ryan, K. S.; Gonzalez, D. J.; Nizet, V.; Proc. Natl. Acad. Sci. U. S. A. 2014, 111, 1957.

79. Shao, Z.; Zhao, H.; Mol. Biosyst. 2011, 7, 1056.

80. Li, M. Z.; Elledge, S. J.; Nat. Methods 2007, 4, 251.

81. Jeong, J.; Yim, H. S.; Ryu, J. Y.; Lee, H. S.; Lee, J. H.; Seen, D. S.; Kang, S. G.; Appl. Environ. Microbiol. 2012, 78, 5440.

82. Gibson, D. G. Young, L.; Chuang, R. Y.; Venter, J. C.; Hutchison, C. A.; Smith, H. O.; Nat. Methods 2009, 6, 343.

83. Kushnir, S.; Sundermann, U.; Yahiaoui, S.; Brockmeyer, A.; Janning, P.; Schulz, F.; Angew. Chem. 2012, 51, 10664.

84. Zhou, Y. Murphy, A. C.; Samborskyy, M.; Prediger, P.; Dias, L. C.; Leadlay, P. F.; Chem. Biol. 2015, 22, 745.

85. de Oliveira, L. G.; Mantovani, S. M.; Quim. Nova 2009, 32, 742.

86. Bibb, M. J.; Janssen, G. R.; Ward, J. M.; Gene 1985, 38, 215.

87. Li, S.; Wang, J.; Li, X.; Yin, S.; Wang, W.; Yang, K.; Microb. Cell. Fact. 2015, 14,1

88. Salis, H. M.; Mirsky, E. A.; Voigt, C. A.; Nat. Biotechnol. 2009, 27, 946.

89. Ro, D. K.; Paradise, E. M.; Ouellet, M.; Fisher, K. J.; Newman, K. L.; Ndungu, J. M.; Ho, K. A.; Eachus, R. A.; Ham, T. S.; Kirby, J.; Chang, M. C. Y.; Withers, S. T.; Shiba, Y.; Sarpong, R.; Keasling, J. D.; Nature 2006, 440,940 